\title{
On the linkages between stock prices and exchange rates: Evidence from the banking crisis of 2007-2010 ts
}

\author{
Guglielmo Maria Caporale, John Hunter, Faek Menla Ali* \\ Department of Economics and Finance, School of Social Sciences, Brunel University, Uxbridge, Middlesex, \\ UB8 $3 P H, U K$
}

\begin{abstract}
This study examines the nature of the linkages between stock market prices and exchange rates in six advanced economies, namely the US, the UK, Canada, Japan, the euro area, and Switzerland, using data on the banking crisis between 2007 and 2010. Bivariate UEDCC-GARCH models are estimated producing evidence of unidirectional Granger causality from stock returns to exchange rate changes in the US and the UK, in the opposite direction in Canada, and bidirectional causality in the euro area and Switzerland. Furthermore, causality-in-variance from stock returns to exchange rate changes is found in the US and in the opposite direction in the euro area and Japan, whilst there is evidence of bidirectional feedback in Switzerland and Canada. The results of the time-varying correlations also show that the dependence between the two variables has increased during the recent financial crisis. These findings imply limited opportunities for investors to diversify their assets during this period.
\end{abstract}

Keywords: Causality-in-variance; Cointegration; Exchange rates; Stock prices

JEL Classification: C32; F31; G15

\footnotetext{
We are grateful for their useful comments to Menelaos Karanasos, James Lothian and participants in the BMRC-QASS conference on Macro and Financial Economics, May $24^{\text {th }}, 2012$, Brunel University, London, UK and the International Conference on the Global Financial Crisis, April 25-26, 2013, University of Southampton, UK.

* Corresponding author: Department of Economics and Finance, School of Social Sciences, Brunel University, Uxbridge, Middlesex, UB8 3PH, UK. Tel:+44(0)1895266107.

Email addresses: Guglielmo-Maria.Caporale @ brunel.ac.uk (G.M. Caporale), John.Hunter@ brunel.ac.uk (J. Hunter),

Faek.Menlaali@brunel.ac.uk (F. Menla Ali).
} 


\section{Introduction}

The collapse on September $15^{\text {th }} 2008$ of Lehman Brothers (LB, until that point the fourth largest investment bank in the US) sent a wave of global panic across financial markets. Following global bank failures and the resulting collapse in liquidity and inter-bank lending, stock market indices in most developed economies experienced significant declines. ${ }^{1}$ Higher uncertainty also generated turbulence in the foreign exchange markets, with the major currencies being hit by a reduction in international transactions and a flight to value. ${ }^{2}$ An interesting issue is whether financial markets have become more dependent as a result of the uncertainty created by the crisis. Aloui, Ben Aissa, and Nguyen (2011), Kenourgios, Samitas, and Paltalidis (2011), Samarakoon (2011), and Dufrénot, Mignon, and PéguinFeissolle (2011) among others find indeed an increase in dependence between international stock markets, and similar findings are reported by Coudert, Couharde, and Mignon (2011) and Bubak, Kočenda, and Žikeš (2011) for foreign exchange markets.

Surprisingly, very few studies have investigated the linkages between stock market prices and exchange rates during the recent crisis. At times of financial turmoil, the high volatility of stock markets generates speculative actions by investors and capital flight to value and this may lead to considerable instability in other markets such as foreign exchange markets. This has been shown in the case of the Asian financial crisis when stock markets led the foreign exchange markets (see, e.g., Granger, Huang, \& Yang, 2000; Caporale, Pittis, \& Spagnolo, 2002). However, in turbulent times, decoupling may also occur: when stock markets experience severe downturns, investors may only focus on markets where

\footnotetext{
${ }^{1}$ From early October 2007 until the second week of March 2009, the S\&P 500 (US), FTSE 350 (UK), and Stoxx 50 Euro (euro area) indices declined by approximately 56\%, 48\%, and 59\%, respectively. Similar stock market falls occurred in Switzerland and Japan, where the lowest points were reached in the second week of March 2009 following peaks on June $1^{\text {st }}$ and July $10^{\text {th }}$, 2007, respectively. The Swiss market index declined by approximately 54\%, whereas the Japanese Nikkei 225 index dropped by roughly $61 \%$ during this period.

${ }^{2}$ Pound Sterling and the Canadian dollar depreciated against the currencies of their trading partners by approximately $30 \%$ (from September 3, 2007 to January 22, 2009) and 28\% (from November 7, 2007 to March 9, 2009), respectively. By contrast, the Japanese yen and Swiss franc appreciated steadily by approximately $38 \%$ and $61 \%$ until late 2011.
} 
their assets can be seen as safe havens irrespective of foreign exchange movements; consequently, there might not be interactions between different markets (see, for example, Hatemi-J \& Roca, 2005).

To the best of our knowledge, the study by Wong and Li (2010) is the only one to date to have examined the interactions between stock prices and exchange rates during the recent crisis; however, it has some limitations. The first is the use of monthly data which cannot capture the timing of events such as the bailouts of AIG in the US and RBS and HBOS in the UK. The second is the fact that their analysis ends in 2008, thereby ignoring the turbulent period following the collapse of LB. The third is their econometric methodology, namely the dynamic conditional correlation (DCC) model of Engle (2002) that was not designed to test for causality-in-variance between the two variables.

The present study aims to address the interactions between stock and exchange rate returns as well as their volatilities and correlations in a comprehensive manner by analysing weekly data for six advanced economies, namely the US, the UK, Canada, Japan, the euro area and Switzerland. Specifically, two sub-periods are examined: the pre-crisis (August 6, 2003-August 8, 2007) and the crisis period (August 15, 2007-December 28, 2011). These are selected to enable us to analyse linkages in both normal and turbulent times, which can provide important insights to investors in terms of portfolio management strategies by focusing their attention on the right segments of the market during such times with the aim of minimising risk and maximising returns in highly integrated financial markets.

The chosen econometric framework is a bivariate VAR-GARCH model, specifically a dynamic version of the unrestricted extended CCC-GARCH developed by Conrad and Karanasos (2010), where each variable's conditional variance is determined by lagged squared shocks and lagged conditional variances of both variables. This approach is flexible enough to capture time-varying correlations and volatility spillovers between stock returns and exchange rate changes. Furthermore, to circumvent potential missing variable errors in the conditional mean, the model is extended to incorporate the underlying short-run deviations between stock prices and exchange rates in the conditional mean in case both variables are cointegrated; the pairwise Engle and Granger (1987), Johansen (1995), and Gregory 
and Hansen (1996) cointegration tests are employed. Therefore, a thorough econometric analysis is conducted of the dependence between stock prices and exchange rates during the period under examination.

The paper is organised as follows. Section 2 provides a brief review of the theoretical and empirical literature on the relationship between stock prices and exchange rates. Section 3 describes the data. Section 4 outlines the econometric methodology. Section 5 discusses the empirical results and Section 6 concludes.

\section{A review of the literature}

There are two main types of theoretical models analysing the linkages between exchange rates and stock prices. The traditional approach based on 'flow-oriented' models (Dornbusch \& Fischer, 1980) posits that causality runs from the former to the latter, whereas the portfolio approach based on 'stock-oriented' models (Branson, 1983; Frankel, 1983) suggests the opposite. In the first case a more competitive exchange rate, assuming that the Marshall-Lerner conditions hold, will improve the trade position of an economy and stimulate the real economy through firm profitability and stock market prices. ${ }^{3}$ However, domestic firms utilising imported inputs will experience an increase in production costs, leading to a reduction in the firms' sales and their earnings, which in turn will lead to a decline in their stock prices. Hence, the impact of exchange rates on stock prices can be either positive or negative.

In the second case, the exchange rate is thought to respond to increases in the demand for financial assets such as bonds and stocks. Hence, a bullish domestic stock market will signal favourable domestic economic prospects, thereby inducing capital inflows and an appreciation of the exchange rate (Kollias, Mylonidis, \& Paleologou, 2012). Another channel for this type of causality stems from the

\footnotetext{
${ }^{3}$ This approach has been given some empirical support in the literature on asset pricing models based on consumption and income (Gregoriou, Hunter, \& Wu, 2009), as well as output (Sousa, 2010).
} 
demand for money (Gavin, 1989). If, however, both traditional and portfolio approaches are empirically relevant, a bidirectional relation between the two variables will be found with an arbitrary correlation (Granger et al., 2000).

The empirical literature also provides mixed results. For example, Aggarwal (1981) found a significant positive correlation between US stock prices and the strength of the US dollar using monthly data between 1974 and 1978, although Soenen and Hennigar (1988) reported that the sign depends on the sample used. Subsequent studies used the two-step cointegration procedure of Engle and Granger (1987) and the maximum likelihood technique of Johansen (1995) to examine the time series properties of both stock prices and exchange rates in the long run. Using monthly data on the US economy for the period 1973-1988, Bahmani-Oskooee and Sohrabian (1992) found that these two variables are not cointegrated, yet there is a bidirectional feedback in the short run. Similar findings were reported by Nieh and Lee (2001), who investigated stock prices and exchange rates for the G7 countries and found one-day significant linkages in some countries.

Cointegration may not be detected as a result of model misspecification, and in particular the omission of variables. Phylaktis and Ravazzolo (2005) found that US stock prices were a key channel linking the exchange rates of five Pacific basin countries to their stock indices. On the other hand, Ülkü and Demirci (2012) showed that global developed and emerging stock market returns explain a large portion of the permanent comovement between stock and foreign exchange markets for eight European emerging economies.

The seminal article of Engle (1982) showed that the ARCH family of models can capture volatility clustering and $\mathrm{ARCH}$ effects in financial returns. Kanas (2000) found positive volatility spillover effects from stock returns to exchange rate changes for all the G7 except Germany. Ning (2010), instead, used copulas to show that there is significant symmetric upper and lower tail dependence between stock and foreign exchange markets for the G5 countries (US, UK, Germany, France and Japan). Katechos (2011) found that the sign of the link between global stock market returns and exchange rates depends on whether the currency in question is a high yielding (positive) or a low 
yielding one (negative). Furthermore, the recent study by Chkili, Aloui, and Nguyen (2012) estimates a bivariate CCC-FIAPARCH specification to capture asymmetry and long memory in daily data from January 1999 to December 2010 for three major European countries (namely France, Germany, and the UK). The authors report a strong correlation between the two variables and more accurate in-sample estimates as well as better out-of-sample performance than in the case of GARCH specifications.

\section{Data description}

We employ weekly data (Wednesday to Wednesday) to analyse the linkages between stock market prices and exchange rates, because daily or intra-daily data are affected by noise and anomalies such as day-of-the-week effects, while monthly data may be inadequate to trace the short-run evolution of capital across international financial markets. We consider six advanced economies: Canada, the euro area, Japan, Switzerland, the UK, and the US from August 6, 2003 to December 28, 2011, a sample of 441 observations. The exchange rates used are trade-weighted (as calculated by the Bank of England), thus providing a better measure of the competitiveness for these economies (Kanas, 2000), while the stock prices are the main local stock exchange indices. The currencies of these economies are the most actively traded in the foreign exchange markets, while their stock markets are the largest among the developed economies in terms of market capitalisation. The data have been obtained from Thomson DataStream.

We consider two sub-periods: a tranquil or pre-crisis period from August 6, 2003 to August 8, 2007, and a crisis period from August 15, 2007 to December 28, 2011. It is well known that the former corresponds to the so-called "Great Moderation" (see Stock \& Watson, 2002), which was characterised by stable and low inflation and a decline in the volatility of other macroeconomic fundamentals. The subsequent global financial crisis (and the associated "Great Recession") clearly represents a new regime. 
The start date of the pre-crisis sample is chosen to avoid the impact of major global events such as the 9/11 terrorist attacks and their anniversary in 2002 (see Gregoriou et al., 2009), and the ensuing conflicts in Afghanistan and Iraq as well as the dotcom bubble that burst in late 2002. On the other hand, the crisis period is defined as starting with the first signs of the subprime mortgage crisis in the US in the summer of 2007, ahead of the failure of Fannie Mae and Freddie Mac and the collapse of LB and AIG. This is also consistent with the study of Melvin and Taylor (2009), who consider August $16^{\text {th }} 2007$ as the beginning of the crisis in the foreign exchange markets.

The variables in levels are denoted by $s_{t}$ and $e_{t}$, respectively the $\log$ stock prices and $\log$ exchange rates, while their first differences $\left(R_{S, t}\right.$ and $\left.R_{E, t}\right)$ are continuously compounded returns; the data are in percentages and are multiplied by 100. A wide range of descriptive statistics are displayed in Table A1 (see Appendix A). Fig.1a and Fig. 1b show the weekly evolution of the trade-weighted exchange rates and stock prices with their corresponding changes for the period under investigation. Stock returns and exchange rate changes exhibit volatility clustering, especially in the crisis period, which indicates an $\mathrm{ARCH}$ model might be appropriate. The Figures also suggest that the $\log$ of exchange rates and stock prices might be non-stationary and follow a stochastic trend, while their first difference is co-variance stationary or has a finite variance. ${ }^{4}$

[Insert Fig. 1a-Fig. 1b about here]

\section{The econometric methodology}

In this study, we employ a bivariate VAR-GARCH model to examine the joint processes governing weekly changes in stock market prices and exchange rates for the two sub-periods. This enables us to explain the dependence between both the first and the second moments of stock returns and exchange rate changes in a dynamic framework. Specifically, in the first step, we specify the

\footnotetext{
${ }^{4}$ This is confirmed by a battery of unit root tests, including the augmented Dickey-Fuller (1981) test, the Phillips and Perron (1988) test and the minimum LM test of Lee and Strazicich (2004) with one structural break in the intercept and the trend.
} 
conditional mean equation by adopting a differenced VAR (Sims, 1980) in case both stock prices and exchange rates are not cointegrated and a vector error correction form (Johansen, 1995) when the variables are cointegrated. Furthermore, the model also includes some exogenous variables to capture the effects of domestic monetary policy shocks as well as global shocks such as those of world stock market and oil prices. The model is then estimated using the dynamic version of the unrestricted extended constant conditional correlation GARCH (UECCC-GARCH) specification developed by Conrad and Karanasos (2010) to capture the joint volatility dynamics between the two variables. ${ }^{5}$

\subsection{Modelling the conditional mean}

Let $R_{t}=\left[R_{S, t}, R_{E, t}\right]$ be the vector containing stock returns $R_{S, t}$ and exchange rate changes $R_{E, t}$. The conditional mean equation is specified as follows:

$$
\begin{gathered}
R_{t}=\mu+\sum_{i=1}^{p} \psi_{i} R_{t-i}+\lambda R_{w, t}+\gamma R_{r f, t}+\delta \Delta P_{o i l, t}+\varepsilon_{t} \\
\mu=\left[\begin{array}{l}
\mu_{S} \\
\mu_{E}
\end{array}\right], \psi_{i}=\left[\begin{array}{cc}
\psi_{S S}^{i} & \psi_{S E}^{i} \\
\psi_{E S}^{i} & \psi_{E E}^{i}
\end{array}\right], \varepsilon_{t}=\left[\begin{array}{c}
\varepsilon_{S, t} \\
\varepsilon_{E, t}
\end{array}\right]
\end{gathered}
$$

The innovation vector $\varepsilon_{t} \mid \Omega_{t-1} \sim N\left(0, H_{t}\right)$ is normally distributed with $H_{t}$ being the corresponding conditional covariance matrix, and $\Omega_{t-1}$ is the information set available at time t-1. $\psi_{S S}^{(i)}$ and $\psi_{E E}^{(i)}$

\footnotetext{
${ }^{5}$ We thank an anonymous referee for suggesting to use a specification which allows for a more meaningful interpretation of the volatility transmission between the two variables (stock returns and exchange rate changes). While the VECH, in comparison to the BEKK, allows for this, estimation of its parameters is computationally demanding as pointed out by Silvennoinen and Teräsvirta (2009). Twenty-one parameters in the variance-covariance equation have to be estimated in the case of two variables in the VECH model and the problem was ill-conditioned as convergence was not achieved in any of the cases considered in our study even when daily data were used.
} 
indicate respectively the response of stock market returns and exchange rate changes to their own lags, whereas $\psi_{E S}^{(i)}$ and $\psi_{S E}^{(i)}$ measure respectively any causality from stock market returns to exchange rate changes, and vice versa. The exogenous variables include $\mathrm{R}_{\mathrm{w}, \mathrm{t}}$ (returns of the world stock index), $\mathrm{R}_{\mathrm{rf}, \mathrm{t}}$ (the three-month domestic interest rate), and $\mathrm{p}_{\mathrm{oil}, \mathrm{t}}$ (the logarithm of the world oil price). ${ }^{6}$ Returns on the world stock market capture shocks from other financial markets around the globe. Interest rates reflect domestic monetary policy and the availability of credit, given that the monetary authorities of the economies considered in this study were operating interest rate rules responding to inflation and an output gap. The oil price can be seen as representing supply shocks; for example Amano and van Norden (1998) showed that world oil price movements can capture the underlying shocks to the terms of trade. Given the nature of the data, in most cases a lag length $p=1$ is sufficient to capture the dynamics associated with financial returns. If necessary, further lags are added to eliminate any serial correlation on the basis of the multivariate $Q$-statistic of Hosking (1981) applied to the standardised residuals $z_{i t}=\varepsilon_{i t} / \sqrt{h_{i t}}$ for $i=S, E$.

Note that in the event of detecting cointegration between stock market prices and exchange rates, (1) is also augmented by a lagged error correction term (ect t-1 $)$ as in Li, Ling, and Wong (2001). The exclusion of an error correction term in the differenced VAR gives rise to a vector moving average term that is generally non-invertible (see Burke \& Hunter, 2005). Cointegration is tested using the pairwise Engle and Granger (1987) test, the Johansen (1995) trace test, and the Gregory and Hansen (1996) method that allows for a single unknown endogenous structural break. Furthermore, if a structural shift in the long-run relationship between stock prices and exchange rates is detected and in order to examine the impact of this shift on the dynamic linkages between the two variables and the short-run adjustment towards the long-run equilibrium, we use a dummy variable and allow the parameters related to Granger

\footnotetext{
${ }^{6}$ Returns on the world stock index for all countries in the sample except the US are represented by returns on the S\&P 500 index. In the case of the US, the world stock index is represented by the MSCI world (excluding the US) index. The world oil price is represented by the West Texas Intermediate Cushing crude oil spot index, US dollars per barrel. The data have been obtained from DataStream.
} 
causality between both variables, denoted by $\psi_{E S}^{i^{*}}$ and $\psi_{S E}^{i^{*}}$, as well as the error correction term, denoted by $\eta^{*}$, to shift as follows:

$$
\begin{aligned}
& R_{t}=\mu+\sum_{i=1}^{p} \psi_{i} R_{t-i}+\lambda R_{w, t}+\gamma R_{r f, t}+\delta \Delta P_{o i l, t}+\eta e c t_{t-1}+\eta^{*} e c t_{t-1}+\varepsilon_{t}, \\
& \psi_{i}=\left[\begin{array}{cc}
\psi_{S S}^{i} & \psi_{S E}^{i}+\psi_{S E}^{i^{*}} \\
\psi_{E S}^{i}+\psi_{E S}^{i^{*}} & \psi_{E E}^{i}
\end{array}\right] .
\end{aligned}
$$

Finally, as Granger causality tests do not provide information on the signs and timing of the relation between stock returns and exchange rate changes, we compute the generalised impulse response functions (GIRFs) of Pesaran and Shin (1998) based on (1) and (2) in order to explore the direction of spillovers between the two variables and their evolution over time.

\subsection{Modelling volatility spillovers}

Having specified the conditional mean equation, a differenced VAR is estimated in the case of no cointegration between the two financial assets, whereas a vector error correction form is adopted when the variables are cointegrated, as stated earlier. The model is then estimated conditional on the multivariate GARCH model to capture the joint volatility dynamics between the two variables. Of the various multivariate GARCH specifications that can be found in the literature, we employ the dynamic conditional correlation model of Engle (2002) allowing for volatility transmission between the two variables in a lead-lag framework by imposing the UECCC-GARCH specification of Conrad and Karanasos (2010). This is given by:

$$
H_{t}=D_{t} R_{t} D_{t} \text {, }
$$


where $\mathrm{D}_{\mathrm{t}}$ is a $2 \times 2$ matrix of the conditional volatilities along the main diagonal, $D_{t}=\operatorname{diag}\left\{\sqrt{h_{i, t}}\right\}$. The common practice in estimating the DCC model is to assume that the conditional volatilities are univariate GARCH processes. In this paper, to allow for the volatility transmission between the two variables, elements of $D_{t}$ are obtained from the multivariate GARCH model instead. Engle (2002) and Caporin and McAleer (2012) argue that consistent estimates of such conditional volatilities can be computed from the multivariate GARCH model.

More specifically, we impose the following structure on the conditional variances:

$h_{t}=\omega+A \varepsilon_{t-1}^{2}+B h_{t-1}$,

where $\omega$ is a vector of constants, and $\mathrm{A}$ and $\mathrm{B}$ are $\mathrm{ARCH}$ and $\mathrm{GARCH}$ parameter matrices:

$\omega=\left[\begin{array}{c}\omega_{S} \\ \omega_{E}\end{array}\right], A=\left[\begin{array}{ll}a_{S S} & a_{S E} \\ a_{E S} & a_{E E}\end{array}\right], B=\left[\begin{array}{ll}b_{S S} & b_{S E} \\ b_{E S} & b_{E E}\end{array}\right]$.

(4) is the UECCC-GARCH model developed by Conrad and Karanasos (2010). ${ }^{7}$ Conrad and Karanasos (2010) derived the necessary and sufficient conditions to ensure $h_{t} \geq 0$, allowing for volatility spillovers of either positive or negative sign. It follows from (4) that each variable's conditional variance is modelled as a function of lagged conditional variances and lagged squared innovations of both variables. Note that (4) is not extended to take into account asymmetric responses, because sign and size bias tests (as in Engle \& $\mathrm{Ng}, 1993$ ) produced no evidence of asymmetry for these two variables. ${ }^{8}$

\footnotetext{
${ }^{7}$ See also Rittler (2012) for an asymmetric unrestricted extended DCC-GARCH model used to examine the relationship between European Union Allowance spot- and future-prices within the second commitment period of the European Union emissions trading scheme.

${ }^{8}$ These results are available upon request from the authors.
} 
Volatility is transmitted between stock returns and exchange rate changes through two channels represented by the off-diagonal parameters in the $\mathrm{ARCH}$ and $\mathrm{GARCH}$ matrices: a symmetric shock $\varepsilon_{i j, t-1}=\varepsilon_{j i, t-1}$ and the conditional variance $h_{i j, t-1}=h_{j i, t-1}$.

Having specified the conditional variances, the correlation in the DCC model is given:

$Q_{t}=\left(1-\alpha^{D C C}-\beta^{D C C}\right) \bar{Q}+\alpha^{D C C} \varepsilon_{t-1} \varepsilon_{t-1}^{\prime}+\beta^{D C C} Q_{t-1}$,

where $Q_{t}=\left(q_{i j, t}\right)$ is the time-varying covariance matrix of $\varepsilon_{t}, \bar{Q}$ is the unconditional covariance matrix of $\varepsilon_{t}$, and $\alpha^{D C C}$ and $\beta^{D C C}$ are non-negative scalar coefficients. The stationarity condition is satisfied as long as $\alpha^{D C C}+\beta^{D C C}<1$. For $\alpha^{D C C}=\beta^{D C C}=0$, the model reduces to the UECCC-GARCH $(1,1)$ specification of Conrad and Karanasos (2010). Furthermore, since $Q_{t}$ does not have unit values on the main diagonal, it is then rescaled to derive the correlation matrix $R_{t}$ :

$$
R_{t}=\operatorname{diag}\left\{Q_{t}\right\}^{-1 / 2} Q_{t} \operatorname{diag}\left\{Q_{t}\right\}^{-1 / 2},
$$

where $\operatorname{diag}\left\{Q_{t}\right\}$ is a matrix containing the main diagonal of $Q_{t}$ and all the off-diagonal elements are zero. A typical element of $R_{t}$ takes the form $\rho_{i j, t}=q_{i j, t} / \sqrt{q_{i i, t} q_{j j, t}}$ for $i, j=S, E$ and $i \neq j$.

We use the quasi-maximum likelihood estimator of Bollerslev and Wooldridge (1992) for all specifications as the corresponding computed standard errors are robust to non-normality in the error process. ${ }^{9}$ We also employ the multivariate Q-statistic (Hosking, 1981) for the squared standardised

\footnotetext{
${ }^{9}$ The procedure was implemented with a convergence criterion of 0.00001, using the quasi-Newton method of Broyden, Fletcher, Goldfarb, and Shanno, which does not require exact estimates of the matrix of second derivatives in contrast to the approach of Berndt, Hall, Hall, and Hausman (see Sargan, 1988).
} 
residuals to determine the adequacy of the estimated model of the conditional variances to capture the multivariate ARCH and GARCH dynamics.

\section{Empirical results}

\subsection{Cointegration test results}

The first step is to examine the time series properties of the stock price and exchange rate series. Then, cointegration is tested using the Gregory and Hansen (1996) procedure which allows for a single unknown structural break. This test is likely to be informative: Campos, Ericsson, and Hendry (1996) and Gregory and Hansen (1996) provided Monte Carlo evidence that the power of a constant parameter cointegration test deteriorates in the presence of a structural break. Not using such tests may lead to the erroneous conclusion that cointegration does not exist when it is present but governed by a structural break.

Allowing for a structural change is likely to be informative for the two sub-periods, pre-crisis and crisis. In the pre-crisis period, economies such as Japan and the euro area have been subjected to significant change. For example, Japan after a decade of deep recession started to recover in the middle of 2005 before being hit by the financial crisis. The euro also underwent significant changes rivalling the US dollar during the pre-crisis period. During the crisis period financial markets were hit by the collapse of LB, the European debt crisis, the downgrade of US government debt, etc. - a regime change might have occurred, with investors reacting differently to the new situations in the markets. ${ }^{10}$

However, since the Gregory and Hansen (1996) test can also detect cointegration with no structural shift, rejection of the null hypothesis of no cointegration may not be due to changes in the

\footnotetext{
${ }^{10}$ The Gregory and Hansen (1996) test is particularly suitable as it allows for a regime change at an unknown date and will likely capture any regime change not detected by the sample split. Using pre-specified break points instead will require prior observation of the data for each country and could introduce pre-testing problems as highlighted by Zivot and Andrews (1992). Furthermore, as pointed out by Cashin, Cespedes, and Sahay (2004) there is not necessarily a one-to-one correspondence between possible causes of a structural shift and its occurrence in the data.
} 
cointegrating relation. Therefore, we also provide estimates of the time-invariant cointegration tests of the pairwise Engle and Granger (1987) test and the Johansen (1995) trace test. If Gregory and Hansen (1996) test provides evidence of cointegration, but the constant parameter cointegration tests of Engle and Granger (1987) and Johansen (1995) do not, then there is evidence of cointegration with a structural shift (see Gregory and Hansen, 1996). On the other hand, if Gregory and Hansen (1996) as well as the conventional cointegration tests of Johansen (1995) and Engle and Granger (1987) provide evidence of cointegration, then following Gregory and Hansen (1996) we use the Hansen (1992) instability test, which is applied to the residuals of a Fully Modified Ordinary Least Squares regression, to determine whether the cointegrating relationship exhibits a structural shift.

The results of the Gregory and Hansen (1996) tests, displayed in Table 1, suggest that the null hypothesis of no cointegration between stock prices and exchange rates is rejected in three cases, in particular for the euro area and Japan in the pre-crisis period, and for the UK in the crisis period. ${ }^{11}$ On the other hand, the results of both Engle and Granger (1987) and Johansen (1995) trace tests, displayed in Table A2 and A3, respectively (see Appendix A), indicate the existence of cointegration only in the case of Japan in the pre-crisis period.

\section{[Insert Table 1 about here]}

While in the euro area in the pre-crisis period and in the UK in the crisis period the cointegrating relation appears to have been subjected to structural change, there is no clear evidence that this was also the case in Japan in the pre-crisis period. However, the Hansen (1992) instability test for this case

\footnotetext{
${ }^{11}$ Note that the long-run relation is perse multi-causal between variables that are primarily endogenous. As long as all series are $I(1)$, neither the regression nor error correction estimates are affected by endogeneity as they are super consistent; the interested reader is directed to the discussion in Davidson and MacKinnon (2004). However, there will be some variation between the estimations and the resulting tests for cointegration in a finite sample (i.e., even though our sample exceeds 100 weekly observations). From the algebra of the problem (Engle and Granger, 1987), in the case of a single cointegrating relation the regression and VAR estimations should give rise to similar parameter estimates irrespective of the way in which the regression is run. In all of the cases where it was possible to observe cointegration we found no evidence for further relations entering the systems estimation and this is supported by the finding of no further serial correlation (see Gregoriou et al., 2009).
} 
implies a rejection of the null hypothesis of cointegration with constant parameters against the alternative of no cointegration due to parameter instability. ${ }^{12}$ This suggests that the cointegrating relation in the case of Japan in the pre-crisis period has also been subjected to a structural shift.

Next, we include the breaks identified by the Gregory and Hansen (1996) tests for the three cases in the VECM models, (2), in order to further capture the structural change in the relation between stock prices and exchange rates. The identified break points are May 25, 2005, for the euro area; October 5, 2005, for Japan; and September 2, 2009, for the UK.

Overall, the results of the cointegration tests suggest that the comovement between stock prices and exchange rates in the euro area and Japan had broken down by the onset of the financial crisis. A possible explanation in the case of Japan is the overvaluation of the yen since 2008. Specifically, the yen hit a record high against the US dollar in late 2011 with the crisis leading to a decoupling of the Japanese stock and foreign exchange markets in the long run relation. For the euro area, the depreciation of the euro and the uncertainty surrounding the single currency since the onset of the crisis might be the reason for the breakdown of the long-run relation. By contrast, it seems that the long-run relation between financial markets in the UK was strengthened by the financial crisis, which led to both series being influenced by similar underlying factors and as a result sharing a single common stochastic trend.

Note that the lack of cointegrating relations may also be the result of misspecification as other fundamental economic variables may work as channels through which the two types of financial markets (stock and foreign exchange markets) are linked in the long run. However, our findings of limited cointegration between stock prices and exchange rates are in line with much of the existing empirical literature (see, e.g., Bahmani-Oskooee \& Sohrabian, 1992; Granger et al., 2000; Nieh \& Lee, 2001; Alagidede, Panagiotidis, \& Zhang, 2011).

\footnotetext{
${ }^{12}$ We use the Lc test to check the stability of the regression parameters. The p-value of the test statistic is 0.01 .
} 


\subsection{Conditional mean results}

The estimates of the conditional mean equation of the bivariate VAR (VECM) UEDCCGARCH model along with associated multivariate Q-statistics (Hosking, 1981) are displayed in Tables 2-7 for Japan, the US, the euro area, Canada, Switzerland, and the UK in turn. Panels A and B concern the pre-crisis and crisis periods, respectively. On the basis of the cointegration tests of subsection 5.1, the lagged error correction terms are included in the conditional mean equations for the cases for which cointegration was detected. Furthermore, since the detected cointegrating relations have been subject to structural change, the short-run Granger causality parameters as well as the lagged error correction terms in the VECM models are allowed to shift at the break points. The Hosking multivariate $Q$ statistics for the standardised residuals indicate no serial correlation at the 5\% level. In all cases, a lag length of 1 captures the dynamics, except for the UK in the pre-crisis sample where $p=3$ and the US and Switzerland in the crisis sample where $p=3$ and $p=5$ are required, respectively (note that the insignificant parameters in the mean equations are excluded). Overall, the estimated models appear to be well specified.

[Insert Tables 2-7 about here]

The dynamic interactions between the first moments of stock returns and exchange rate changes, captured by $\psi_{E S}^{(i)}$ and $\psi_{S E}^{(i)}$, suggest that there are limited dynamic linkages between the two variables in the pre-crisis compared with the crisis period. The results for the pre-crisis period imply the existence of unidirectional short-run Granger causality from stock returns to exchange rate changes in the case of Japan, while there is short-run causality in the opposite direction in the UK. Since lagged error correction terms are included in the cases of cointegration, the VECM model will allow one to differentiate between the short-run and long-run Granger causality. Specifically, long-run causality between the two variables will be through the error correction term if this is negative and significant as, for example, in Japan in the equations for both stock returns and exchange rate changes. This implies 
that both variables adjust to the steady-state equilibrium in Japan, and there is bidirectional long-run feedback. However, the speed of adjustment of exchange rate changes towards equilibrium becomes slower after the break on October 5, 2005 as $\eta_{E}^{*}$ is positive and significant. ${ }^{13}$ By contrast, the lagged error correction term in the euro area is negative and significant only in the equation for exchange rate changes, suggesting that the adjustment towards equilibrium takes place through this variable.

In the crisis period, instead, the results indicate the existence of short-run Granger causality from stock returns to exchange rate changes in the US and the UK, in the opposite direction in Canada, and bidirectional short-run causality in the euro area and Switzerland. With regard to the UK, the lagged error correction term computed from the estimation of a cointegrating relation of the exchange rate on the stock price is found to be negative and significant in the equation for exchange rate changes, implying an adjustment mechanism through the exchange rate and ensuring the evidence of causality from stock returns to exchange rate changes in the long run.

In contrast to the case of Japan (in the pre-crisis period), the impact of the breaks, identified by the Gregory and Hansen (1996) tests in the previous subsection, on the linkages between stock returns and exchange rate changes in the euro area (in the pre-crisis period) and the UK (in the crisis period) seem to be limited, hence the causal structure between the two variables as well as the speed of adjustment towards the equilibrium are stable in these two cases. The significant change in the speed of adjustment of the exchange rate towards equilibrium in the case of Japan (in the pre-crisis period) may be due to the acceleration in the depreciation of the yen as a result of the decline in the Japanese longterm real interest rates compared to those for the US over the period April 2005 to June 2006 (Obstfeld, 2009).

To analyse further the dynamic linkages between stock returns and exchange rate changes, we estimate the GIRFs of Pesaran and Shin (1998) for the cases where Granger causality is not rejected. Overall, the results of the GIRFs (8 periods) from one standard error shock of the variable in question,

\footnotetext{
${ }^{13}$ Note that the error correction term is calculated from the estimation of a cointegrating relation of the stock price on the exchange rate.
} 
displayed respectively in Fig. $2 \mathrm{a}$ and Fig. $2 \mathrm{~b}$ for the pre-crisis and crisis periods, are in line with the findings for Granger causality. In the pre-crisis period (see Fig. 2a), a one standard error shock to stock returns in Japan leads to an appreciation of the yen in the first week. This is line with the portfolio approach on the linkage between stock prices and exchange rates, suggesting that stock prices lead exchange rates with a positive correlation. In the UK, the response of stock returns to a one standard error shock to exchange rate changes is significant and positive in the third week. This is consistent with the traditional approach on the linkage between the two variables, suggesting that exchange rates lead stock prices. However, the sign of the correlation can go either way depending on whether the domestic firm is an exporter or an importer. The net effect on the aggregate stock index cannot be determined a priori and hence the sign can be either positive or negative (Granger et al., 2000).

With regard to the crisis period (see Fig. 2b), it is found that a one standard deviation shock to stock returns results in a depreciation of the exchange rate in the UK, which is not consistent with the portfolio approach, unlike in the US, where the positive sign supports empirically this approach. In Canada a shock to exchange rates decreases stock returns, in line with the traditional approach.

In Switzerland a shock to stock returns has a positive impact on corresponding exchange rates in the first week, whilst the response of stock returns to a shock to exchange rates is negative and significant in the third week. Finally, exchange rate changes (stock returns) in the euro area respond negatively (positively) to a shock to stock returns (exchange rate changes).

[Insert Fig. 2a-2b about here]

Granger et al. (2000) concluded that capital flows played a major role in the interactions between stock prices and exchange rates during the Asian flu period. Fig. 3 shows the evolution of portfolio investment liabilities and current accounts as a percentage of GDP for all countries over the sample period considered here. The empirical support for the portfolio approach found for the US could be the result of capital flows. Given that the US was the centre of the crisis, the decline in its stock market at the onset of the crisis in late 2007, along with the collapse of LB and the downgrade of its debt status, induced capital outflows (see Fig. 3) and a depreciation of its currency. With regard to the UK, the 
collapse of LB in the US and the shutdown of their offices in London sent a wave of panic right through the UK stock market followed by a severe downturn ${ }^{14}$ and major changes in the British pound over the crisis period. Nonetheless, the causal effect as measured from the impulse responses seems to be more complex than implied by the portfolio approach as the sign does not validate such an approach, as stated earlier.

\section{[Insert Fig. 3 about here]}

By contrast, Canada experienced capital inflows as opposed to outflows during the crisis (see Fig. 3) and its currency strengthened after 2009 (see Fig. 1a) leading its stock market. The lack of any interactions between stock returns and exchange rate changes in Japan, on the other hand, can be attributed to country-specific factors. The fact that Japan has amassed huge foreign exchange reserves and had a strengthening real economy played a significant role in the appreciation of its currency and making it immune to the crisis (Wong \& Li, 2010). The finding also reflects the overall state of the Asian and Australasian countries whose banks and economies appeared not to be contaminated by the crisis that has been linked to the failure of the valuation of complex derivatives.

As far as the exogenous variables in the conditional mean equations are concerned, the return on the world stock index exerts strong influence on stock returns and exchange rate changes in most cases, especially in the crisis period, suggesting its dominance in the transmission of shocks and information to other markets around the globe. The impact of the domestic interest rate, by contrast, appears to be limited. This reinforces the notion that the quantitative easing policies adopted by the monetary authorities throughout the crisis period were ineffective. One possible explanation is that the economic cycle did not respond because of the breakdown of both the financial system and the monetary transmission mechanism via the banks.

With regard to the influence of world oil price changes, this increased in the crisis period compared with the pre-crisis one in most countries, except Switzerland. The effects on stock returns in

\footnotetext{
${ }^{14}$ According to Alistair Darling, the then Chancellor of the Exchequer, liquidity was compromised so that there was a fear that the cash machines would be empty.
} 
the case of Switzerland, in the pre-crisis period, and Canada and the UK, in the crisis period, are consistent with the findings of Filis, Degiannakis, and Floros (2011), who argued that stock markets react positively to demand-side oil price shocks. The two periods in this study are characterised by such shocks. The pre-crisis period was accompanied by an increase in oil prices because of an increase in demand, primarily in China, whereas in the crisis period there was a decline in oil prices as a consequence of the global recession induced by the financial crisis. The increased impact of oil price changes on exchange rate changes in the crisis period compared with the pre-crisis one, on the other hand, is in line with the findings of Roboredo (2011). During the crisis, the impact on the US dollar and Japanese yen is negative, whereas for the British pound, the Canadian dollar, and the euro is positive, consistently with the findings of Lizardo and Mollick (2010).

\subsection{Volatility spillovers results}

In the previous subsection, we provide an analysis of the dynamic linkages between stock returns and exchange rate changes in terms of the first moment across the two sub-periods examined. Now we analyse the estimated joint volatility dynamics between the two variables across the two sub-periods.

The estimates of the conditional variance equations as well as the dynamic correlations in the UEDCC-GARCH models are reported in Tables 8-13 for Japan, the US, the euro area, Canada, Switzerland, and the UK, respectively. Panels A and B concern the pre-crisis and crisis periods, respectively. The reported Hosking multivariate Q-statistics of order (6) and (12) for the squared standardised residuals suggests at the $5 \%$ significance level that the multivariate GARCH $(1,1)$ structure adequately captures volatility, and hence no further variance dynamics are required. The results also suggest that the stationarity condition of Engle (2002) and the non-negativity conditions of Conrad and Karanasos (2010) are fulfilled. Furthermore, in each panel, we test four hypotheses. The first is that the conditional variances follow univariate GARCH models by restricting $\alpha_{S E}=\alpha_{E S}=b_{S E}=b_{E S}=0$. The second and the third test for causality-in-variance from stock returns to exchange rate changes by setting 
$\alpha_{E S}=b_{E S}=0$ and in the reverse direction by setting $\alpha_{S E}=b_{S E}=0$. Finally, we test for no time-varying correlation between stock returns and exchange rate changes by restricting $\alpha^{D C C}=\beta^{D C C}=0$. These tests are conducted using a likelihood ratio test statistic $\mathrm{LR}=-2\left(\mathrm{~L}_{\mathrm{r}}-\mathrm{L}_{\mathrm{ur}}\right) \sim \chi_{\mathrm{df}}^{2}$, where $\mathrm{L}_{\mathrm{r}}$ and $\mathrm{L}_{\mathrm{ur}}$ denote the restricted and unrestricted log-likelihood function values and the LR statistic follows the chi-squared distribution with degrees of freedom equal to the number of restricted parameters.

[Insert Tables 8-13 about here]

The results suggest that the stock price-exchange rate process in the two sub-periods displays strong conditional heteroscedasticity: the diagonal elements of the ARCH matrices are positive and significant in $75 \%$ of the cases in the pre-crisis period and $91.6 \%$ of the cases in the crisis period. The conditional variances, on the other hand, exhibit persistence in all cases with only one exception, i.e., UK exchange rate changes in the pre-crisis period. More specifically, the estimated conditional variances of stock returns range from 0.72 (the lowest) for Switzerland to 0.91 (the highest) for Japan in the pre-crisis period, whilst they range from 0.75 (the lowest) for the UK to 0.92 (the highest) for Japan in the crisis period. The corresponding estimates of exchange rate changes range from 0.64 (Japan) to 0.95 (euro area) in the pre-crisis period and from 0.77 (Switzerland) to 0.93 (Japan) in the crisis period.

Furthermore, the off-diagonal elements of the ARCH and GARCH matrices indicate that shocks to exchange rate changes (stock returns) affect the conditional variance of stock returns (exchange rate changes) in the euro area and Canada across the two sub-periods, the UK in the pre-crisis period, and Japan, Switzerland and the US in the crisis period. More specifically, in the pre-crisis period, we observe volatility spillovers from exchange rate changes to stock returns $\left(b_{S E}\right)$ in all countries, shock spillovers from exchange rate changes to stock returns $\left(\alpha_{S E}\right)$ in the UK and Canada, and shock spillovers in the reverse direction $\left(\alpha_{E S}\right)$ in the US. In the crisis period, lagged shocks and volatilities of both variables affect both variables' volatilities in Canada and Switzerland. In Japan, while there is bidirectional volatility spillovers between the two variables, lagged shocks of exchange rate changes 
affect the volatility of stock returns. The findings also indicate that the volatility of exchange rate changes in the US reacts significantly to the lagged volatility of stock returns, whilst the volatility of stock returns in the euro area is affected significantly by lagged shocks to exchange rate changes.

Overall, the results of the likelihood ratio tests suggest the existence of causality-in-variance operating as a flow of information from exchange rate changes to stock returns for the UK, Switzerland, Canada and the euro area in the pre-crisis period. These findings imply that during normal times it is the volatility of exchange rates that leads that of stock prices. In the crisis period, there is evidence of causality-in-variance from stock returns to exchange rate changes in the US and in the opposite direction in the euro area and Japan. Furthermore, there is a bidirectional feedback for Switzerland and Canada, whilst there is no evidence of causality-in-variance for the UK.

Finally, the results suggest that the two series exhibit time-varying correlation in the two subperiods in most cases. Specifically, at the $10 \%$ level, the null hypothesis $H_{0}: \alpha^{D C C}=\beta^{D C C}=0$ is rejected in all cases, except for Canada in the pre-crisis period. Fig. 4a and $4 \mathrm{~b}$ show the evolution of the dynamic conditional correlation between the two series respectively for the pre-crisis and crisis periods to provide further insights into the dependence between the two variables. It is evident that the correlation between stock returns and exchange rate changes is time-varying in the two sub-periods in most cases. Furthermore, the average correlations between the two variables in the pre-crisis (crisis) period are found to be $0.16(0.58), 0.03(0.34),-0.12(-0.62),-0.33(-0.40),-0.19(0.02)$, and $-0.14(-$ 0.26) for Canada, the euro area, Japan, Switzerland, the UK, and the US, respectively. These findings are consistent with the causality-in-variance tests. Therefore these two types of financial markets appear to have become more dependent in all countries, except the UK, during the recent financial crisis.

[Insert Fig. 4a and 4b here] 


\section{Conclusions}

In this study, we have analysed the nature of the linkages between stock market returns and exchange rate changes in six advanced economies, namely the US, the UK, Canada, Japan, the euro area, and Switzerland. Specifically, we have examined the extent to which they have been affected by the banking crisis of 2007-2010 employing weekly data from August 2003 to December 2011. The estimation of bivariate UEDCC-GARCH models provides evidence of unidirectional short-run Granger causality from stock returns to exchange rate changes in the US and the UK, in the opposite direction in Canada, and of bidirectional feedback in the euro area and Switzerland during the recent financial crisis. Furthermore, causality-in-variance tests for the crisis period lend support to the existence of causalityin-variance from stock returns to exchange rate changes in the US, in the opposite direction in the euro area and Japan, and of bidirectional feedback in Switzerland and Canada. Our findings are consistent with those of Granger et al. (2000) and Caporale et al. (2002), who examined the 1997 Asian financial crisis.

The results reflect cross-country differences in terms of policies, cycle phases, expectations, the degree of liberalisation, and capital controls (Nieh \& Lee, 2001). Furthermore, given the fact that the currencies under investigation are the most actively traded and the corresponding economies are the top trading partners, their heterogeneous strength throughout the financial crisis may have played an important role in generating capital flows into and out of these countries. This might be one of the reasons for the different results when analysing the interactions between stock returns and exchange rate changes in these economies.

Finally, our findings also imply the existence of limited diversification opportunities on a domestic basis during financial crises. Since stock prices and exchange rates have been shown to be interlinked strongly within national economies, it follows that investors cannot use them as effective instruments for portfolio hedging and diversification strategies. This applies to all countries examined except the UK. 


\section{Appendix A}

[Insert Tables A1-A3 about here]

\section{References}

Aggarwal, R. (1981). Exchange rates and stock prices: A study of the U.S. capital markets under floating exchange rates. Akron Business and Economic Review, 12, 7-12.

Alagidede, P., Panagiotidis, T., \& Zhang, X. (2011). Causal relationship between stock prices and exchange rates. The Journal of International Trade \& Economic Development, 20, 67-86.

Aloui, R., Ben Aissa, M. S., \& Nguyen, D. K. (2011). Global financial crisis, extreme interdependences, and contagion effects: The role of economic structure? Journal of Banking and Finance, 35, 130141.

Amano, R. A., \& van Norden, S. (1998). Oil prices and the rise and fall of the US real exchange rate. Journal of International Money and Finance, 17, 299-316.

Bahmani-Oskooee, M., \& Sohrabian, A. (1992). Stock prices and the effective exchange of the dollar. Applied Economics, 24, 459-464.

Bollerslev, T. P., \& Wooldridge, J. M. (1992). Quasi-maximum likelihood estimation and inference in dynamic models with time-varying covariances. Econometric Reviews, 11, 143-172.

Branson, W. H. (1983). Macroeconomic determinants of real exchange rate risk. In R. J. Herring, (Ed.), Managing foreign exchange rate risk. Cambridge, MA: Cambridge University Press, 33-74.

Bubák, V., Kočenda, E., \& Žikeš, F. (2011). Volatility transmission in emerging European foreign exchange markets. Journal of Banking and Finance, 35, 2829-2841.

Burke, S. P., \& Hunter, J. (2005). Modelling non-stationary economic time series: A multivariate approach. Basingstoke: Palgrave. 
Campos, J., Ericsson, N. R., \& Hendry, F. (1996). Cointegration tests in the presence of structural breaks. Journal of Econometrics, 70, 187-220.

Caporale, G. M., Pittis, N., \& Spagnolo, N. (2002). Testing causality-in-variance: An application to the East Asian markets. International Journal of Finance and Economics, 7, 235-245.

Caporin, M., \& McAleer, M. (2012). Do we really need both BEKK and DCC? A tale of two multivariate GARCH models. Journal of Economic Surveys, 26, 736-751.

Cashin, P., Cespedes, L. F., \& Sahay, R. (2004). Commodity currencies and the real exchange rate. Journal of Development Economics, 75, 239-268.

Chkili, W., Aloui, C., \& Nguyen, D. K. (2012). Asymmetric effects and long memory in dynamic volatility relationships between stock returns and exchange rates. Journal of International Financial Markets, Institutions \& Money, 22, 738-757.

Conrad, C., \& Karanasos, M., 2010. Negative volatility spillovers in the unrestricted ECCC-GARCH model. Econometric Theory, 26, 838-862.

Coudert, V., Couharde, C., \& Mignon, V. (2011). Exchange rate volatility across financial crises. Journal of Banking and Finance, 35, 3010-3018.

Davidson, R., \& MacKinnon, J. G. (2004). Econometric theory and methods. New York: Oxford University Press.

Dickey, D. A., \& Fuller, W. A. (1981). Likelihood ratio statistics for autoregressive time series with a unit root. Econometrica, 49, 1057-1072.

Dornbusch, R., \& Fischer, S. (1980). Exchange rates and the current account. The American Economic Review, 70, 960-971.

Dufrénot, G., Mignon, V., \& Péguin-Feissolle, A. (2011). The effects of the subprime crisis on the Latin American financial markets: An empirical assessment. Economic Modelling, 28, 2342-2357.

Engle, R. F. (1982). Autoregressive conditional heteroskedasticity with estimates of the variance of U.K. inflation. Econometrica, 50, 987-1008. 
Engle, R. F. (2002). Dynamic conditional correlation: A simple class of multivariate GARCH models. Journal of Business \& Economic Statistics, 20, 339-350.

Engle, R. F., \& Granger, C. W. J. (1987). Co-integration and error correction: Representation, estimation, and testing. Econometrica, 55, 251-276.

Engle, R. F., \& Ng, V. K. (1993). Measuring and testing the impact of news on volatility. Journal of Finance, 48, 1749-1778.

Filis, G., Degiannakis, S., \& Floros, C. (2011). Dynamic correlation between stock market and oil prices: The case of oil-importing and oil-exporting countries. International Review of Financial Analysis, 20, 152-164.

Frankel, J. A. (1983). Monetary and portfolio balance models of exchange rate determination. In J. S. Bhandari, \& B. H. Putnam, (Eds.), Economic interdependence and flexible exchange rates. Cambridge, MA: MIT Press, 84-115.

Gavin, M. (1989). The stock market and exchange rate dynamics. Journal of International Money and Finance, 8, 181-200.

Granger, C. W. J., Huang, B-N., \& Yang, C-W. (2000). A bivariate causality between stock prices and exchange rates: Evidence from recent Asian flu. The Quarterly Review of Economics and Finance, $40,337-354$

Gregoriou, A., Hunter, J., \& Wu, F. (2009). An empirical investigation of the relationship between the real economy and stock returns for the United States. Journal of Policy Modeling, 31, 133-143.

Gregory, A. W., \& Hansen, B. E. (1996). Residual-based tests for cointegration in models with regime shifts. Journal of Econometrics, 70, 99-126.

Hansen, B. (1992). Tests for parameter instability in regressions with I(1) processes. Journal of Business \& Economic Statistics, 10, 321-335.

Hatemi-J, A., \& Roca, E. (2005). Exchange rates and stock prices interactions during good and bad times: Evidence from the ASEAN4 countries. Applied Financial Economics, 15, 539-546. 
Hosking, J. R. M. (1981). Equivalent forms of the multivariate portmanteau statistic. Journal of the Royal Statistical Society, 43, 261-262.

Johansen, S. (1995). Likelihood-based inference in cointegrated vector autoregressive model. Oxford: Oxford University Press.

Kanas, A. (2000). Volatility spillover between stock returns and exchange rate changes: International evidence. Journal of Business Finance \& Accounting, 27, 447-467.

Katechos, G. (2011). On the relationship between exchange rates and equity returns: A new approach. Journal of International Financial Markets, Institutions \& Money, 21, 550-559.

Kenourgios, D., Samitas. A., \& Paltalidis, N. (2011). Financial crises and stock market contagion in a multivariate time-varying asymmetric framework. Journal of International Financial Markets, Institutions \& Money, 21, 92-106.

Kollias, C., Mylonidis, N., \& Paleologou, S-M. (2012). The nexus between exchange rates and stock markets: Evidence from the euro-dollar rate and composite European stock indices using rolling analysis. Journal of Economics and Finance, 36, 136-147.

Lee, J., \& Strazicich, M. C. (2004). Minimum LM unit root test with one structural break. Appalachian State University Working Paper Series No 04-17.

Li, W. K., Ling, S., \& Wong, H. (2001). Estimation for partially nonstationary multivariate autoregressive models with conditional heteroscedasticity. Biometrica, 88, 1135-1152.

Lizardo, R., \& Mollick, A. (2010). Oil price fluctuations and U.S. dollar exchange rates. Energy Economics, 32, 399-408.

Ljung, G. M., \& Box, G .E. P. (1978). On a measure of lack of fit in time series models. Biometrika, 65, 297-303.

MacKinnon, J. G. (1991). Critical values for cointegration tests. In R. F. Engle, \& C. W. J. Granger, (Eds.), Long-run economic relationships: Readings in cointegration. Oxford: Oxford University Press, 267-276.

Melvin, M., \& Taylor, M. P. (2009). The crisis in the foreign exchange market. Journal of International 
Money and Finance, 28, 1317-1330.

Nieh, C-C., \& Lee, C-F. (2001). Dynamic relationships between stock prices and exchange rates for G-7 countries. The Quarterly Review of Economics and Finance, 41, 477-490.

Ning, C. (2010). Dependence structure between the equity market and the foreign exchange market-A copula approach. Journal of International Money and Finance, 29, 743-759.

Obstfeld, M. (2009). Time of troubles: The yen and Japan's economy, 1985-2008. Mimeo, University of California at Berkeley.

Pesaran, H. H., Shin, Y. (1998). Generalized impulse response analysis in linear multivariate models. Economics Letters, 58, 17-29.

Phillips, P. C. B., \& Perron, P. (1988). Testing for a unit root in time series regression. Biometrika, 75, 335-346.

Phylaktis, K., \& Ravazzolo, F. (2005). Stock prices and exchange rate dynamics. Journal of International Money and Finance, 24, 1031-1053.

Rittler, D. (2012). Price discovery and volatility spillovers in the European Union emissions trading scheme: A high-frequency analysis. Journal of Banking \& Finance, 36, 774-785.

Roboredo, J. C. (2011). Modelling oil price and exchange rate co-movements. Journal of Policy Modeling, 34, 419-440.

Samarakoon, L. P. (2011). Stock market interdependence, contagion, and the U.S. financial crisis: The case of emerging and frontier markets. Journal of International Financial Markets, Institutions \& Money, 21, 724-742.

Sargan, J. D. (1988). Lectures on advanced econometric theory. Oxford: Basil Blackwell.

Silvennoinen, A., \& Teräsvirta, T. (2009). Multivariate GARCH models. In T. G. Andersen, R. A. Davis, J-P. Kreiß, \& T. V. Mikosch, (Eds.), Handbook of financial time series. Berlin Heidelberg: Springer, 201-229.

Sims, C. A. (1980). Macroeconomics and reality. Econometrica, 48, 1- 48. 
Soenen, L. A., \& Hennigar, E. S. (1988). An analysis of exchange rates and stock prices-The U.S. experience between 1980 and 1986. Akron Business and Economic Review, 19, 7-16.

Sousa, R. M. (2010). Consumption (dis)aggregate wealth and asset returns. Journal of Empirical Finance, 17, 606-622.

Stock, J. H., \& Watson, M. H. (2002). Has the business cycle changed and why? NBER macroeconomics annual. Cambridge, MA: MIT press.

Ülkü, N., \& Demirci, E. (2012). Joint dynamics of foreign exchange and stock markets in emerging Europe. Journal of International Financial Markets, Institutions \& Money, 22, 55-86.

Wong, D. K. T., \& Li, K-W. (2010). Comparing the performance of relative stock return differential and real exchange rate in two financial crises. Applied Financial Economics, 20, 137-150.

Zivot, E., \& Andrews, D. (1992). Further evidence of great crash, the oil price shock and unit root hypothesis. Journal of Business and Economic Statistics, 10, 251-270. 


\section{Table 1}

Results of Gregory and Hansen (1996)' cointegration tests allowing for a shift at an unknown date.

\begin{tabular}{|c|c|c|c|c|c|c|c|}
\hline Regression & Model & US & UK & Euro area & Canada & Japan & Switzerland \\
\hline \multicolumn{8}{|c|}{ Panel A: Pre-crisis period $(6 / 8 / 2003$ - 8/8/2007) } \\
\hline \multirow[t]{5}{*}{$s_{t}$ on $e_{t}$} & $\bar{C}$ & $\begin{array}{c}-3.191(0) \\
{[2005: 10: 12]}\end{array}$ & $\begin{array}{c}-3.081(4) \\
{[2004: 03: 17]}\end{array}$ & $\begin{array}{c}-3.828(5) \\
{[2005: 07: 13]}\end{array}$ & $\begin{array}{c}-3.670(7) \\
{[2006: 09: 20]}\end{array}$ & $\begin{array}{c}-4.702(6)^{* *} \\
{[2005: 10: 05]}\end{array}$ & $\begin{array}{c}-4.020(7) \\
{[2004: 04: 21]}\end{array}$ \\
\hline & $\mathrm{C} / \mathrm{T}$ & $-4.535(8)$ & $-4.638(8)$ & $-4.900(8)$ & $-4.056(3)$ & $-4.826(0)$ & $-3.902(1)$ \\
\hline & & [2007:01:10] & [2004:05:26] & [2004:05:26] & [2004:06:09] & [2005:10:19] & [2005:10:12] \\
\hline & $\mathrm{C} / \mathrm{S}$ & $-4.535(0)$ & $-3.178(4)$ & $-3.873(3)$ & $-3.869(0)$ & $-4.555(6)$ & $-4.161(1)$ \\
\hline & & {$[-4.53539]$} & [2005:05:18] & {$[2005: 04: 20]$} & [2006:12:20] & [2005:10:05] & [2005:07:20] \\
\hline \multirow{6}{*}{$e_{t}$ on $s_{t}$} & $\mathrm{C}$ & $-3.534(0)$ & $-3.759(4)$ & $-3.456(5)$ & $-3.469(7)$ & $-4.068(6)$ & $-4.019(0)$ \\
\hline & & [2005:06:08] & [2006:09:13] & [2005:07:13] & [2006:09:20] & [2006:09:06] & [2004:04:21] \\
\hline & $\mathrm{C} / \mathrm{T}$ & $-3.767(0)$ & $-3.600(5)$ & $-5.048(0)^{* * *}$ & $-3.536(7)$ & $-4.454(6)$ & $-4.677(0)$ \\
\hline & & [2005:06:08] & [2006:09:06] & [2005:05:25] & [2006:09:20] & [2004:11:10] & [2004:05:26] \\
\hline & $\mathrm{C} / \mathrm{S}$ & $-4.537(0)$ & $-3.836(4)$ & $-3.498(5)$ & $-3.874(0)$ & $-4.338(6)$ & $-4.069(0)$ \\
\hline & & [2005:06:08] & [2006:06:14] & [2005:07:13] & [2006:12:20] & [2006:07:12] & [2004:05:26] \\
\hline \multicolumn{8}{|c|}{ Panel B: Crisis period $(15 / 8 / 2007-28 / 12 / 2011)$} \\
\hline \multirow{6}{*}{$s_{t}$ on $e_{t}$} & $\mathrm{C}$ & $-3.840(0)$ & $-4.408(0)$ & $-2.823(7)$ & $-3.113(0)$ & $-3.563(0)$ & $-2.966(5)$ \\
\hline & & [2008:10:01] & [2009:09:02] & [2008:08:06] & [2008:11:26] & [2009:12:16] & [2008:08:27] \\
\hline & $\mathrm{C} / \mathrm{T}$ & $-4.247(0)$ & $-4.433(0)$ & $-3.106(8)$ & $-3.137(8)$ & $-4.041(0)$ & $-3.133(0)$ \\
\hline & & [2008:10:01] & [2009:09:02] & [2008:07:30] & [2008:11:26] & [2008:06:04] & [2008:09:24] \\
\hline & $\mathrm{C} / \mathrm{S}$ & $-4.286(0)$ & $-4.842(0)$ & $-2.659(7)$ & $-3.099(8)$ & $-4.336(0)$ & $-3.746(5)$ \\
\hline & & [2008:09:10] & [2009:05:13] & [2008:08:06] & [2008:11:12] & [2009:07:15] & [2009:09:30] \\
\hline \multirow{6}{*}{$e_{t}$ on $s_{t}$} & $\mathrm{C}$ & $-3.530(5)$ & $-4.561(0)$ & $-3.706(7)$ & $-3.221(8)$ & $-3.598(0)$ & $-2.898(6)$ \\
\hline & & [2008:08:27] & [2009:09:02] & [2010:03:17] & [2009:08:05] & [2009:12:16] & [2010:06:30] \\
\hline & $\mathrm{C} / \mathrm{T}$ & $-4.234(6)$ & $-4.454(0)$ & $-3.953(7)$ & $-3.195(8)$ & $-4.069(0)$ & $-3.792(5)$ \\
\hline & & [2010:02:03] & [2008:11:19] & [2010:03:17] & [2009:07:29] & [2008:06:04] & [2010:10:20] \\
\hline & $\mathrm{C} / \mathrm{S}$ & $-3.447(5)$ & $-5.124(0)^{* *}$ & $-3.963(7)$ & $-3.288(8)$ & $-3.919(0)$ & $-3.207(6)$ \\
\hline & & [2008:04:23] & [2009:09:02] & [2010:04:14] & [2009:12:16] & [2009:12:16] & [2010:04:14] \\
\hline
\end{tabular}

The test due to Gregory and Hansen (1996) is conducted by regressing $s_{t}$ on $e_{t}$ and the reverse regression. Model $C$ allows for a shift in the intercept, Model $C / T$ allows for a shift in the intercept and the trend, and Model $C / S$ allows for a shift in both the intercept and the slope coefficient of the cointegrating relationship. The corresponding critical values for each model are from Table 1 in Gregory and Hansen (1996). The lag order is chosen on the basis of $t$-tests in parenthesis (.) subject to a maximum of 8 lags. Breakpoints are in square brackets [.].

*** significant at $5 \%$. 


\section{Table 2}

The estimated conditional mean equation for Japan.

\begin{tabular}{|c|c|c|c|c|c|}
\hline \multicolumn{3}{|c|}{ Panel A: Pre-crisis period (6/8/2003-8/8/2007) } & \multicolumn{3}{|c|}{ Panel B: Crisis period $(15 / 8 / 2007-28 / 12 / 2011)$} \\
\hline & $R_{S, t}(i=S)$ & $R_{E, t}(i=E)$ & & $R_{S, t}(i=S)$ & $R_{E, t}(i=E)$ \\
\hline$\mu_{i}$ & $\begin{array}{c}0.026 \\
(0.134)\end{array}$ & $-{ }_{(0.059)}^{0.186^{\text {******* }}}$ & $\mu_{i}$ & $-{ }_{(0.101)}^{0.212^{* * *}}$ & $\begin{array}{c}0.334^{\text {***** }} \\
(0.081)\end{array}$ \\
\hline$\psi_{S i, t-1}$ & $\begin{array}{c}0.139^{* *} \\
(0.056)\end{array}$ & & $\psi_{E i, t-1}$ & & $-{ }_{(0.031)}^{0.143^{* * * *}}$ \\
\hline$\psi_{E i, t-1}$ & $\frac{0.062^{\text {****** }}}{(0.024)}$ & & $\lambda_{i}$ & $\underbrace{0.992^{\text {粰 }}}_{(0.059)}$ & $-{ }_{(0.041)}^{0.313^{* * *}}$ \\
\hline$\eta_{i}$ & $-{ }^{3.420^{* *} *}$ & $-\underbrace{5.484^{* * * * *}}_{(1.038)}$ & $\delta_{i}$ & & $-\underbrace{0.055^{* * *}}_{(0.022)}$ \\
\hline$\eta_{i}^{*}$ & & $\underset{(1.750)}{4.409 *}$ & & & \\
\hline$\lambda_{i}$ & ${ }_{(0.096)}^{0.964^{\text {***** }}}$ & & & & \\
\hline Loglik & -735.734 & & Loglik & -951.217 & \\
\hline$Q(6)$ & $21.097[0$ & & $Q(6)$ & $14.063[0$ & \\
\hline$Q(12)$ & $35.964[0$ & & $Q(12)$ & $43.500[0$ & \\
\hline
\end{tabular}

$R_{S, t}$ and $R_{E, t}$ indicate stock market returns and exchange rate changes, respectively. Heteroscedasticity-consistent standard errors are in parentheses (.), whereas $p$-values are reported in [.]. $Q(p)$ is the multivariate Hosking (1981) test for the $p^{\text {th }}$ order serial correlation on the standardised residuals $z_{i t}$, where $i=S$ (for stock returns), $E$ (for exchange rate changes). The conditional mean equation in the pre-crisis period is specified as $R_{t}=\mu+\sum_{i=1}^{p} \psi_{i} R_{t-i}+\lambda R_{w, t}+\gamma R_{r f, t}+\delta \Delta P_{o i l, t}+\eta e c t_{t-1}+\eta^{*} e c t_{t-1}+\varepsilon_{t}$, where $\psi_{i}=\left[\begin{array}{ll}\psi_{S S}^{i} & \psi_{S E}^{i}+\psi_{S E}^{i^{*}} \\ \psi_{E S}^{i}+\psi_{E S}^{i^{*}} & \psi_{E E}^{i}\end{array}\right]$, $R_{w, t}, R_{r f, t}$ and $\Delta P_{o i l, t}$ indicate returns of the world stock index, domestic interest rate and changes in oil prices, respectively. The conditional mean equation in the crisis period is specified as $R_{t}=\mu+\sum_{i=1}^{p} \psi_{i} R_{t-i}+\lambda R_{w, t}+\gamma R_{r f, t}+\delta \Delta P_{o i l, t}+\varepsilon_{t}$. Insignificant parameters are excluded.

*** significant at $1 \%$.

** significant at $5 \%$. 
Table 3

The estimated conditional mean equation for the US.

\begin{tabular}{|c|c|c|c|c|c|}
\hline \multicolumn{3}{|c|}{ Panel A: Pre-crisis period (6/8/2003-8/8/2007) } & \multicolumn{3}{|c|}{ Panel B: Crisis period (15/8/2007-28/12/2011) } \\
\hline & $R_{S, t}(i=S)$ & $R_{E, t}(i=E)$ & & $R_{S, t}(i=S)$ & $R_{E, t}(i=E)$ \\
\hline$\mu_{i}$ & $\underset{(0.040)}{0.013}$ & $\underset{(0.057)}{0.048}$ & $\mu_{i}$ & $\underset{(0.131)}{0.092}$ & $-\underset{(0.074)}{0.043}$ \\
\hline$\psi_{S i, t-1}$ & $-e_{(0.039)}^{0.219^{* * * * * * *}}$ & & $\psi_{S i, t-1}$ & $-{ }_{(0.038)}^{0.080^{* * *}}$ & \\
\hline$\lambda_{i}$ & $\frac{0.613^{\text {****** }}}{(0.037)}$ & $-0.215^{\text {***** }}$ & $\psi_{E i, t-1}$ & $\underset{(0.034)}{0.071^{* *}}$ & \\
\hline \multirow[t]{4}{*}{$\delta_{i}$} & $-\underbrace{0.023^{* * * *}}_{(0.008)}$ & & $\psi_{E i, t-2}$ & & $\underbrace{0.101^{* * * * *}}_{(0.039)}$ \\
\hline & & & $\psi_{S i, t-3}$ & $\underbrace{0.051^{*}}_{(0.030)}$ & \\
\hline & & & $\lambda_{i}$ & $\frac{0.917^{\text {****** }}}{(0.044)}$ & $-\underbrace{0.168^{\text {**** }}}_{(0.031)}$ \\
\hline & & & $\delta_{i}$ & & $-\underbrace{0.032^{* * *}}_{(0.014)}$ \\
\hline Loglik & -598.707 & & Loglik & -881.698 & \\
\hline$Q(6)$ & $16.550[0$ & & $Q(6)$ & $20.170[0$ & \\
\hline$Q(12)$ & $39.624[0$ & & $Q(12)$ & $43.029[0$ & \\
\hline
\end{tabular}

$R_{S, t}$ and $R_{E, t}$ indicate stock market returns and exchange rate changes, respectively. Heteroscedasticity-consistent standard errors are in parentheses (.), whereas $p$-values are reported in [.]. $Q(p)$ is the multivariate Hosking (1981) test for the $p^{\text {th }}$ order serial correlation on the standardised residuals $z_{i t}$, where $i=S$ (for stock returns), $E$ (for exchange rate changes). The conditional mean equation in the pre-crisis and crisis period is specified as $R_{t}=\mu+\sum_{i=1}^{p} \psi_{i} R_{t-i}+\lambda R_{w, t}+\gamma R_{r f, t}+\delta \Delta P_{o i l, t}+\varepsilon_{t}$, where $R_{w, t}, R_{r f, t}$ and $\Delta P_{o i l, t}$ indicate returns of the world stock index, domestic interest rate and changes in oil prices, respectively. Insignificant parameters are excluded. $* * *$ significant at $1 \%$.

** significant at $5 \%$.

* significant at $10 \%$. 


\section{Table 4}

The estimated conditional mean equation for the euro area.

\begin{tabular}{|c|c|c|c|c|c|}
\hline \multicolumn{3}{|c|}{ Panel A: Pre-crisis period (6/8/2003-8/8/2007) } & \multicolumn{3}{|c|}{ Panel B: Crisis period (15/8/2007-28/12/2011) } \\
\hline & $R_{S, t}(i=S)$ & $R_{E, t}(i=E)$ & & $R_{S, t}(i=S)$ & $R_{E, t}(i=E)$ \\
\hline$\mu_{i}$ & $\begin{array}{l}0.081 \\
(0.065)\end{array}$ & $-\underset{(0.128)}{0.192}$ & $\mu_{i}$ & $-\underset{(0.428)}{0.432}$ & $-\underbrace{0.184^{* * *}}_{(0.084)}$ \\
\hline$\eta_{i}$ & & $-\underbrace{6.583^{* * * *}}_{(2.610)}$ & $\psi_{S i, t-1}$ & $-\underbrace{0.194^{* * * *}}_{(0.046)}$ & $\begin{array}{c}0.378^{* * *} \\
(0.169)\end{array}$ \\
\hline$\lambda_{i}$ & $\begin{array}{c}0.845^{* * * *} \\
(0.050)\end{array}$ & & $\psi_{E i, t-1}$ & $-{ }_{(0.016)}^{0.034^{* *}}$ & \\
\hline \multirow[t]{3}{*}{$\gamma_{i}$} & & $\underset{(0.039)}{0.081^{* *}}$ & $\lambda_{i}$ & $\underset{(0.055)}{0.877^{* * * * *}}$ & ${ }_{(0.021)}^{0.096^{* * * * *}}$ \\
\hline & & & $\gamma_{i}$ & & $\underbrace{0.043^{* *}}_{(0.021)}$ \\
\hline & & & $\delta_{i}$ & & $\underset{(0.015)}{0.058^{* * * * *}}$ \\
\hline Loglik & -572.848 & & Loglik & -895.994 & \\
\hline$Q(6)$ & $26.603[0$ & & $Q(6)$ & $22.306[0$ & \\
\hline$Q(12)$ & $49.968[0$ & & $Q(12)$ & $60.301[0$ & \\
\hline
\end{tabular}

$R_{S, t}$ and $R_{E, t}$ indicate stock market returns and exchange rate changes, respectively. Heteroscedasticity-consistent standard errors are in parentheses (.), whereas $p$-values are reported in [.]. $Q(p)$ is the multivariate Hosking (1981) test for the $p^{\text {th }}$ order serial correlation on the standardised residuals $z_{i t}$, where $i=S$ (for stock returns), $E$ (for exchange rate changes). The conditional mean equation in the pre-crisis period is specified as $R_{t}=\mu+\sum_{i=1}^{p} \psi_{i} R_{t-i}+\lambda R_{w, t}+\gamma R_{r f, t}+\delta \Delta P_{o i l, t}+\eta e c t_{t-1}+\eta^{*} e c t_{t-1}+\varepsilon_{t}$, where $\psi_{i}=\left[\begin{array}{ll}\psi_{S S}^{i} & \psi_{S E}^{i}+\psi_{S E}^{i^{*}} \\ \psi_{E S}^{i}+\psi_{E S}^{i^{*}} & \psi_{E E}^{i}\end{array}\right]$, $R_{w, t}, R_{r f, t}$ and $\Delta P_{o i l, t}$ indicate returns of the world stock index, domestic interest rate and changes in oil prices, respectively. The conditional mean equation in the crisis period is specified as $R_{t}=\mu+\sum_{i=1}^{p} \psi_{i} R_{t-i}+\lambda R_{w, t}+\gamma R_{r f, t}+\delta \Delta P_{o i l, t}+\varepsilon_{t}$. Insignificant parameters are excluded.

*** significant at $1 \%$.

** significant at $5 \%$.

* significant at $10 \%$. 


\section{Table 5}

The estimated conditional mean equation for Canada.

\begin{tabular}{|c|c|c|c|c|c|}
\hline \multicolumn{3}{|c|}{ Panel A: Pre-crisis period (6/8/2003-8/8/2007) } & \multicolumn{3}{|c|}{ Panel B: Crisis period (15/8/2007-28/12/2011) } \\
\hline & $R_{S, t}(i=S)$ & $R_{E, t}(i=E)$ & & $R_{S, t}(i=S)$ & $R_{E, t}(i=E)$ \\
\hline$\mu_{i}$ & $0.175^{* *}$ & $\begin{array}{c}0.093 \\
(0.074)\end{array}$ & $\mu_{i}$ & $-\underset{(0.101)}{0.132}$ & $\begin{array}{c}0.024 \\
(0.066)\end{array}$ \\
\hline \multirow[t]{4}{*}{$\lambda_{i}$} & $\begin{array}{c}0.831^{\text {***** }} \\
(0.067)\end{array}$ & $\begin{array}{c}0.176^{\text {******* }} \\
0.057\end{array}$ & $\psi_{S i, t-1}$ & & $-\underset{(0.354)}{0.859^{* * *}}$ \\
\hline & & & $\psi_{E i, t-1}$ & & $-\underset{(0.199)}{0.357^{*}}$ \\
\hline & & & $\lambda_{i}$ & 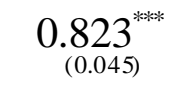 & $0_{(0.034)}^{0.556^{* * * *}}$ \\
\hline & & & $\delta_{i}$ & $\begin{array}{c}0.136^{* * * * *} \\
(0.018)\end{array}$ & $\begin{array}{c}0.069^{\text {********* }} \\
(0.017)\end{array}$ \\
\hline Loglik & -665.613 & & Loglik & -906.713 & \\
\hline$Q(6)$ & $18.811[0$ & & $Q(6)$ & $27.308[0$ & \\
\hline$Q(12)$ & $45.179[0$ & & $Q(12)$ & $54.148[0$ & \\
\hline
\end{tabular}

$R_{S, t}$ and $R_{E, t}$ indicate stock market returns and exchange rate changes, respectively. Heteroscedasticity-consistent standard errors are in parentheses (.), whereas $p$-values are reported in [.]. $Q(p)$ is the multivariate Hosking (1981) test for the $p^{\text {th }}$ order serial correlation on the standardised residuals $z_{i t}$, where $i=S$ (for stock returns), $E$ (for exchange rate changes). The conditional mean equation in the pre-crisis and crisis period is specified as $R_{t}=\mu+\sum_{i=1}^{p} \psi_{i} R_{t-i}+\lambda R_{w, t}+\gamma R_{r f, t}+\delta \Delta P_{o i l, t}+\varepsilon_{t}$, where $R_{w, t}, R_{r f, t}$ and $\Delta P_{o i l, t}$ indicate returns of the world stock index, domestic interest rate and changes in oil prices, respectively. Insignificant parameters are excluded. $* * *$ significant at $1 \%$.

** significant at $5 \%$.

* significant at $10 \%$. 
Table 6

The estimated conditional mean equation for Switzerland.

\begin{tabular}{|c|c|c|c|c|c|}
\hline \multicolumn{3}{|c|}{ Panel A: Pre-crisis period (6/8/2003-8/8/2007) } & \multicolumn{3}{|c|}{ Panel B: Crisis period (15/8/2007-28/12/2011) } \\
\hline & $R_{S, t}(i=S)$ & $R_{E, t}(i=E)$ & & $R_{S, t}(i=S)$ & $R_{E, t}(i=E)$ \\
\hline$\mu_{i}$ & $0.161^{* * *}$ & $-\underset{(0.022)}{0.011}$ & $\mu_{i}$ & $-\underset{(0.180)}{0.066}$ & $0.160^{\text {****k }}$ \\
\hline$\psi_{S i, t-1}$ & $-\underbrace{0.083^{* * *}}_{(0.038)}$ & & $\psi_{S i, t-1}$ & $-{ }_{(0.055)}^{0.198^{* * *}}$ & \\
\hline$\lambda_{i}$ & $\underset{(0.060)}{0.822^{* * * * k}}$ & $-\underbrace{0.049^{* *}}_{(0.023)}$ & $\psi_{E i, t-1}$ & $\underset{(0.033)}{0.101^{\text {****** }}}$ & \\
\hline \multirow[t]{4}{*}{$\delta_{i}$} & $\begin{array}{c}0.053^{*} \\
(0.029)\end{array}$ & & $\psi_{S i, t-3}$ & & $-{ }_{(0.101)}^{0.193^{*}}$ \\
\hline & & & $\psi_{E i, t-4}$ & & $-\underbrace{0.178^{* * * *}}_{(0.072)}$ \\
\hline & & & $\psi_{E i, t-5}$ & & $-{ }_{(0.073)}^{0.221^{* * * *}}$ \\
\hline & & & $\lambda_{i}$ & $\underset{(0.044)}{0.712^{\text {****** }}}$ & $-\underbrace{0.090^{* * * *}}_{(0.016)}$ \\
\hline Loglik & -507.889 & & Loglik & -842.977 & \\
\hline$Q(6)$ & $28.958[0$ & & $Q(6)$ & $29.843[0$ & \\
\hline$Q(12)$ & $60.797[0$ & & $Q(12)$ & $56.919[0$ & \\
\hline
\end{tabular}

$R_{S, t}$ and $R_{E, t}$ indicate stock market returns and exchange rate changes, respectively. Heteroscedasticity-consistent standard errors are in parentheses (.), whereas $p$-values are reported in [.]. $Q(p)$ is the multivariate Hosking (1981) test for the $p^{\text {th }}$ order serial correlation on the standardised residuals $z_{i t}$, where $i=S$ (for stock returns), $E$ (for exchange rate changes). The conditional mean equation in the pre-crisis and crisis period is specified as $R_{t}=\mu+\sum_{i=1}^{p} \psi_{i} R_{t-i}+\lambda R_{w, t}+\gamma R_{r f, t}+\delta \Delta P_{o i l, t}+\varepsilon_{t}$, where $R_{w, t}, R_{r f, t}$ and $\Delta P_{o i l, t}$ indicate returns of the world stock index, domestic interest rate and changes in oil prices, respectively. Insignificant parameters are excluded.

$* * *$ significant at $1 \%$.

** significant at $5 \%$.

* significant at $10 \%$. 
Table 7

The estimated conditional mean equation for the UK.

\begin{tabular}{|c|c|c|c|c|c|}
\hline \multicolumn{3}{|c|}{$\overline{\text { Panel A: Pre-crisis period (6/8/2003-8/8/2007) }}$} & \multicolumn{3}{|c|}{ Panel B: Crisis period (15/8/2007-28/12/2011) } \\
\hline & $R_{S, t}(i=S)$ & $R_{E, t}(i=E)$ & \multirow[b]{2}{*}{$\mu_{i}$} & \multirow{2}{*}{$\begin{array}{c}R_{S, t}(i=S) \\
-0.131 \\
(0.142)\end{array}$} & \multirow{2}{*}{$\begin{array}{c}R_{E, t}(i=E) \\
-0.053^{* *} \\
(0.025)\end{array}$} \\
\hline$\mu_{i}$ & $\begin{array}{c}0.069^{*} \\
(0.720)\end{array}$ & $\begin{array}{c}0.058 \\
(0.045)\end{array}$ & & & \\
\hline$\psi_{S i, t-1}$ & $-\underset{(0.054)}{0.092^{*}}$ & & $\psi_{S i, t-1}$ & $-{ }_{(0.040)}^{0.148^{* * * *}}$ & \\
\hline$\psi_{S i, t-3}$ & & $\begin{array}{c}0.263^{* *} \\
(0.113)\end{array}$ & $\psi_{E i, t-1}$ & $-{ }_{(0.033)}^{0.069^{* *}}$ & \\
\hline$\psi_{E i, t-3}$ & & $-\underset{(0.072)}{0.123^{* * *}}$ & $\eta_{i}$ & & $-{ }_{(0.694)}^{2.951^{* * * *}}$ \\
\hline \multirow[t]{2}{*}{$\lambda_{i}$} & $0.676^{* * * * *}$ & & $\lambda_{i}$ & $\begin{array}{c}0.756^{* * * * *} \\
(0.053)\end{array}$ & \\
\hline & & & $\delta_{i}$ & $\begin{array}{c}0.081^{* * * *} \\
(0.026)\end{array}$ & $\underbrace{0.048^{* * * * *}}_{(0.017)}$ \\
\hline Loglik & -574.234 & & Loglik & -915.689 & \\
\hline$Q(6)$ & 25.987[ & & $Q(6)$ & $22.426[0$ & \\
\hline$Q(12)$ & 45.382[ & & $Q(12)$ & $50.870[0$ & \\
\hline
\end{tabular}

$R_{S, t}$ and $R_{E, t}$ indicate stock market returns and exchange rate changes, respectively. Heteroscedasticity-consistent standard errors are in parentheses (.), whereas $p$-values are reported in [.]. $Q(p)$ is the multivariate Hosking (1981) test for the $p^{\text {th }}$ order serial correlation on the standardised residuals $z_{i t}$, where $i=S$ (for stock returns), $E$ (for exchange rate changes). The conditional mean equation in the pre-crisis period is specified as $R_{t}=\mu+\sum_{i=1}^{p} \psi_{i} R_{t-i}+\lambda R_{w, t}+\gamma R_{r f, t}+\delta \Delta P_{o i l, t}+\varepsilon_{t}$, where $R_{w, t}, R_{r f, t}$ and $\Delta P_{o i l, t}$ indicate returns of the world stock index, domestic interest rate and changes in oil prices, respectively. The conditional mean equation in the crisis period is $R_{t}=\mu+\sum_{i=1}^{p} \psi_{i} R_{t-i}+\lambda R_{w, t}+\gamma R_{r f, t}+\delta \Delta P_{o i l, t}+\eta e c t_{t-1}+\eta^{*} e c t_{t-1}+\varepsilon_{t}$, where $\psi_{i}=\left[\begin{array}{lc}\psi_{S S}^{i} & \psi_{S E}^{i}+\psi_{S E}^{i^{*}} \\ \psi_{E S}^{i}+\psi_{E S}^{i^{*}} & \psi_{E E}^{i}\end{array}\right]$.

Insignificant parameters are excluded.

*** significant at $1 \%$.

$* *$ significant at $5 \%$.

* significant at $10 \%$. 
Table 8

The estimated bivariate UEDCC-GARCH model for Japan.

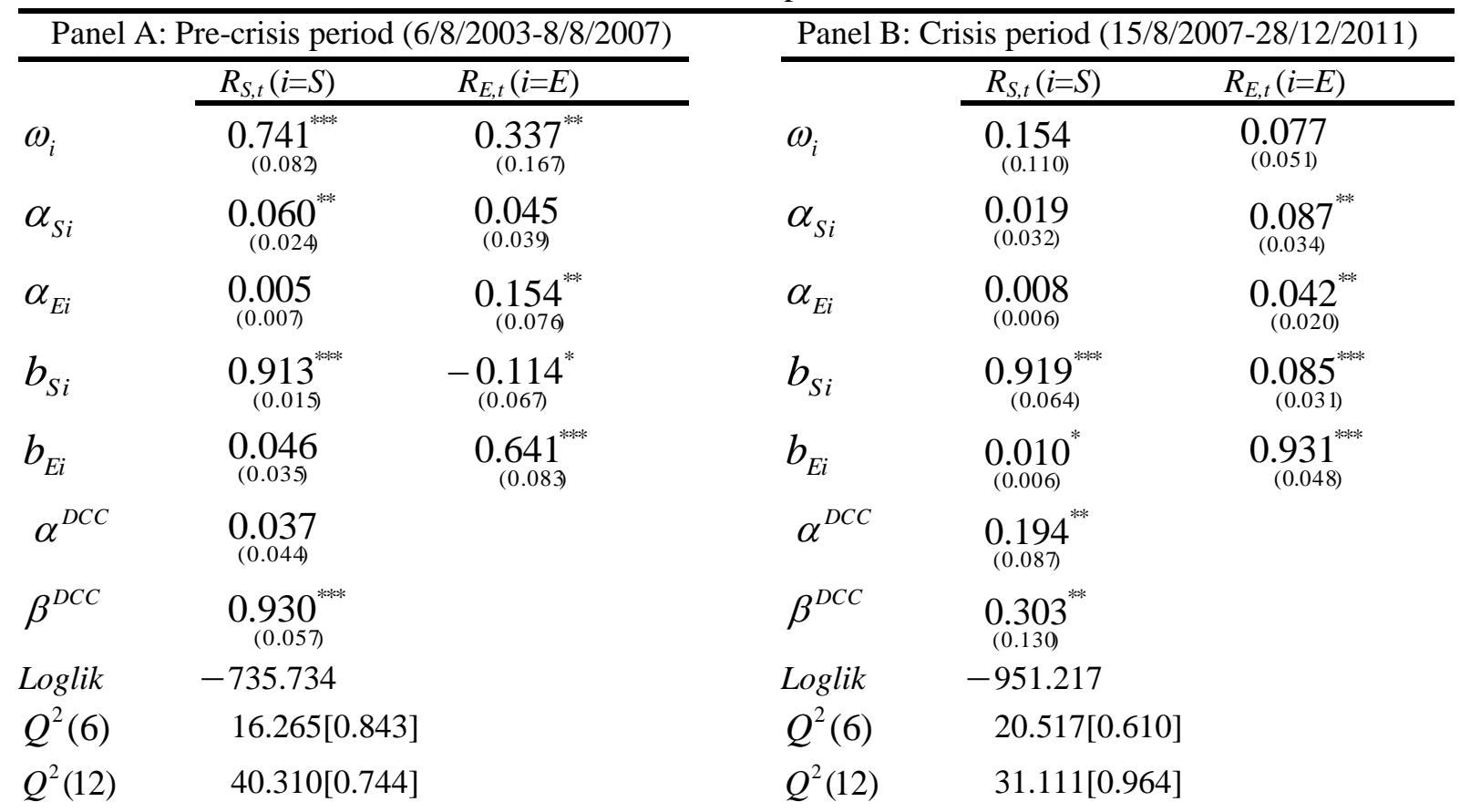

\section{Hypotheses Testing}

(i) No causality-in-variance between $R_{S, t}$ and $R_{E, t}$ Hypotheses Testing

(i) No causality-in-variance between $R_{S, t}$ and $R_{E, t}$ $H_{0}: \alpha_{S E}=\alpha_{E S}=b_{S E}=b_{E S}=0 \quad L R=3.96[0.410]$ $H_{0}: \alpha_{S E}=\alpha_{E S}=b_{S E}=b_{E S}=0 \quad L R=40.6[0.000]$ (ii) No causality-in-variance from $R_{S, t}$ to $R_{E, t}$

$$
H_{0}: \alpha_{E S}=b_{E S}=0 \quad L R=0.21[0.896]
$$

(ii) No causality-in-variance from $R_{S, t}$ to $R_{E, t}$

$$
H_{0}: \alpha_{E S}=b_{E S}=0
$$

(iii) No causality-in-variance from $R_{E, t}$ to $R_{S, t}$

$$
H_{0}: \alpha_{S E}=b_{S E}=0 \quad L R=2.05[0.357]
$$

(iii) No causality-in-variance from $R_{E, t}$ to $R_{S, t}$

$$
H_{0}: \alpha_{S E}=b_{S E}=0
$$

(iv) No time-varying correlation

(iv) No time-varying correlation

$$
H_{0}: \alpha^{D C C}=\beta^{D C C}=0 \quad L R=54.2[0.000] \quad H_{0}: \alpha^{D C C}=\beta^{D C C}=0 \quad L R=5.42[0.066]
$$

$\overline{R_{S, t}}$ and $R_{E, t}$ indicate stock market returns and exchange rate changes, respectively; while $L R$ indicates likelihood ratio test statistics. Heteroscedasticity-consistent standard errors are in parentheses (.), whereas $p$-values are reported in [.]. $Q^{2}(p)$ is the multivariate Hosking (1981) test for the $p^{\text {th }}$ order serial correlation on the squared standardised residuals $z_{i t}^{2}$, where $i=S$ (for stock returns), $E$ (for exchange rate changes). The conditional variance equation is specified as $h_{t}=\omega+A \varepsilon_{t-1}^{2}+B h_{t-1}$. The dynamic correlation is specified as $Q_{t}=\left(1-\alpha^{D C C}-\beta^{D C C}\right) \bar{Q}+\alpha^{D C C} \varepsilon_{t-1} \varepsilon_{t-1}^{\prime}+\beta^{D C C} Q_{t-1}$.

**** significant at $1 \%$.

*** significant at $5 \%$.

* significant at $10 \%$. 


\section{Table 9}

The estimated bivariate UEDCC-GARCH model for the US.

\begin{tabular}{|c|c|c|c|c|c|}
\hline \multicolumn{3}{|c|}{ Panel A: Pre-crisis period (6/8/2003-8/8/2007) } & \multicolumn{3}{|c|}{ Panel B: Crisis period $(15 / 8 / 2007-28 / 12 / 2011)$} \\
\hline & $R_{S, t}(i=S)$ & $R_{E, t}(i=E)$ & \multirow[b]{2}{*}{$\omega_{i}$} & \multirow{2}{*}{$\begin{array}{c}R_{S, t}(i=S) \\
\begin{array}{c}1.133 \\
(1.131)\end{array}\end{array}$} & \multirow{2}{*}{$\begin{array}{c}R_{E, t}(i=E) \\
0.098^{* * *} \\
(0.046)\end{array}$} \\
\hline$\omega_{i}$ & $\begin{array}{c}0.454 \\
(0.299)\end{array}$ & $\begin{array}{l}0.030 \\
(0.107)\end{array}$ & & & \\
\hline$\alpha_{S i}$ & $\underbrace{0.066^{* *}}_{(0.031)}$ & $\underset{(0.091)}{0.131}$ & $\alpha_{S i}$ & $\frac{0.210^{* * *}}{(0.084)}$ & $\begin{array}{l}0.585 \\
(0.638)\end{array}$ \\
\hline$\alpha_{E i}$ & $\begin{array}{c}0.050^{*} \\
(0.026)\end{array}$ & $\begin{array}{c}0.051^{* * * * * *} \\
(0.016)\end{array}$ & $\alpha_{E i}$ & $\begin{array}{c}0.005 \\
(0.005)\end{array}$ & ${ }^{0.055^{* * *}}$ \\
\hline$b_{S i}$ & $\begin{array}{c}0.790^{\text {**** }} \\
(0.107)\end{array}$ & $-\underset{(0.025)}{0.049^{*}}$ & $b_{S i}$ & $\begin{array}{c}0.768^{* * w^{*}} \\
(0.178)\end{array}$ & $-\underset{(1.442)}{0.134}$ \\
\hline$b_{E i}$ & $\begin{array}{c}0.020 \\
(0.048)\end{array}$ & $\begin{array}{c}0.891_{(0.117)}^{\text {***** }} \\
\end{array}$ & $b_{E i}$ & ${ }_{(0.014)}^{0.045^{* * * x+1}}$ & $\begin{array}{c}0.810^{\text {********* }} \\
(0.075)\end{array}$ \\
\hline$\alpha^{D C C}$ & $\begin{array}{c}0.018 \\
(0.033)\end{array}$ & & $\alpha^{D C C}$ & $0.117^{* * w^{*}}$ & \\
\hline$\beta^{D C C}$ & $\begin{array}{l}0.791^{\text {******* }} \\
(0.111)\end{array}$ & & $\beta^{D C C}$ & $\begin{array}{c}0.868^{* * x_{*}} \\
(0.040)\end{array}$ & \\
\hline Loglik & -598.707 & & Loglik & -881.698 & \\
\hline$Q^{2}(6)$ & $17.902[0$ & & $Q^{2}(6)$ & $9.704[0$ & \\
\hline$Q^{2}(12)$ & $39.824[0$ & & $Q^{2}(12)$ & $47.63[0$ & \\
\hline
\end{tabular}

\section{Hypotheses Testing}

(i) No causality-in-variance between $R_{S, t}$ and $R_{E, t}$ Hypotheses Testing

(i) No causality-in-variance between $R_{S, t}$ and $R_{E, t}$ $H_{0}: \alpha_{S E}=\alpha_{E S}=b_{S E}=b_{E S}=0 \quad L R=4.28[0.368]$ $H_{0}: \alpha_{S E}=\alpha_{E S}=b_{S E}=b_{E S}=0 \quad L R=25.9[0.000]$

(ii) No causality-in-variance from $R_{S, t}$ to $R_{E, t}$

$$
H_{0}: \alpha_{E S}=b_{E S}=0 \quad L R=4.53[0.103]
$$

(ii) No causality-in-variance from $R_{S, t}$ to $R_{E, t}$

(iii) No causality-in-variance from $R_{E, t}$ to $R_{S, t}$

$$
H_{0}: \alpha_{E S}=b_{E S}=0
$$

$L R=16.7[0.000]$

(iii) No causality-in-variance from $R_{E, t}$ to $R_{S, t}$

$$
H_{0}: \alpha_{S E}=b_{S E}=0 \quad L R=2.19[0.333]
$$$$
H_{0}: \alpha_{S E}=b_{S E}=0
$$

(iv) No time-varying correlation

(iv) No time-varying correlation

$$
H_{0}: \alpha^{D C C}=\beta^{D C C}=0 \quad L R=5.72[0.057] \quad H_{0}: \alpha^{D C C}=\beta^{D C C}=0 \quad L R=6.33[0.042]
$$

$R_{S, t}$ and $R_{E, t}$ indicate stock market returns and exchange rate changes, respectively; while $L R$ indicates likelihood ratio test statistics. Heteroscedasticity-consistent standard errors are in parentheses (.), whereas $p$-values are reported in [.]. $Q^{2}(p)$ is the multivariate Hosking (1981) test for the $p^{\text {th }}$ order serial correlation on the squared standardised residuals $z_{i t}^{2}$, where $i=S$ (for stock returns), $E$ (for exchange rate changes). The conditional variance equation is specified as $h_{t}=\omega+A \varepsilon_{t-1}^{2}+B h_{t-1}$. The dynamic correlation is specified as $Q_{t}=\left(1-\alpha^{D C C}-\beta^{D C C}\right) \bar{Q}+\alpha^{D C C} \varepsilon_{t-1} \varepsilon_{t-1}^{\prime}+\beta^{D C C} Q_{t-1}$.

**** significant at $1 \%$.

*** significant at $5 \%$

" significant at $10 \%$. 
Table 10

The estimated bivariate UEDCC-GARCH model for the euro area.

\begin{tabular}{|c|c|c|}
\hline \multicolumn{3}{|c|}{ Panel A: Pre-crisis period (6/8/2003-8/8/2007) } \\
\hline & $R_{S, t}(i=S)$ & $R_{E, t}(i=E)$ \\
\hline$\omega_{i}$ & $\begin{array}{c}0.486^{*} \\
(0.286)\end{array}$ & $\begin{array}{c}0.060 \\
(0.091)\end{array}$ \\
\hline$\alpha_{S i}$ & $\begin{array}{l}0.047 \\
(0.047)\end{array}$ & $\begin{array}{l}0.019 \\
(0.018)\end{array}$ \\
\hline$\alpha_{E i}$ & $\begin{array}{c}0.0002 \\
(0.0002\end{array}$ & 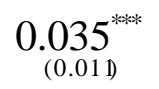 \\
\hline$b_{S i}$ & 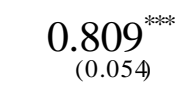 & 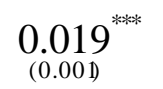 \\
\hline$b_{E i}$ & $\begin{array}{l}0.016 \\
(0.020)\end{array}$ & $\begin{array}{c}0.953^{* * * * *} \\
(0.013)\end{array}$ \\
\hline$\alpha^{D C C}$ & $\begin{array}{c}0.078^{* * *} \\
(0.038)\end{array}$ & \\
\hline$\beta^{D C C}$ & $\begin{array}{c}0.823^{\text {*Noke }} \\
(0.175)\end{array}$ & \\
\hline Loglik & -572.848 & \\
\hline$Q^{2}(6)$ & $21.809[0$ & \\
\hline$Q^{2}(12)$ & $33.225[0$ & \\
\hline
\end{tabular}

\section{Hypotheses Testing}

(i) No causality-in-variance between $R_{S, t}$ and $R_{E, t}$

\begin{tabular}{|c|c|c|}
\hline \multicolumn{3}{|c|}{ Panel B: Crisis period $(15 / 8 / 2007-28 / 12 / 2011)$} \\
\hline & $R_{S, t}(i=S)$ & $R_{E, t}(i=E)$ \\
\hline$\omega_{i}$ & $0_{(0.414)}^{0.892^{* * *}}$ & $\begin{array}{c}0.030 \\
(0.100)\end{array}$ \\
\hline$\alpha_{S i}$ & $\begin{array}{c}0.318^{* * *} \\
(0.129)\end{array}$ & $\underset{(0.050)}{0.179^{* * * * * *}}$ \\
\hline$\alpha_{E i}$ & $\begin{array}{c}0.0009 \\
(0.0008)\end{array}$ & $0.120^{0 * 038)}$ \\
\hline$b_{S i}$ & $\underset{(0.103)}{0.802^{* * * * *}}$ & $\begin{array}{l}0.077 \\
(0.052)\end{array}$ \\
\hline$b_{E i}$ & $\begin{array}{c}0.012 \\
(0.016)\end{array}$ & ${ }_{(0.073)}^{0.786}$ \\
\hline$\alpha^{D C C}$ & $\begin{array}{c}0.003 \\
(0.043)\end{array}$ & \\
\hline$\beta^{D C C}$ & $\begin{array}{c}0.864^{* * * * * * *} \\
(0.099)\end{array}$ & \\
\hline Loglik & -895.994 & \\
\hline$Q^{2}(6)$ & $8.359[0.997]$ & \\
\hline$Q^{2}(12)$ & 26.38[0.993] & \\
\hline
\end{tabular}
Hypotheses Testing

(i) No causality-in-variance between $R_{S, t}$ and $R_{E, t}$ $H_{0}: \alpha_{S E}=\alpha_{E S}=b_{S E}=b_{E S}=0 \quad L R=22.40[0.000]$ $H_{0}: \alpha_{S E}=\alpha_{E S}=b_{S E}=b_{E S}=0 \quad L R=11.58[0.020]$

(ii) No causality-in-variance from $R_{S, t}$ to $R_{E, t}$

$$
H_{0}: \alpha_{E S}=b_{E S}=0 \quad L R=2.76[0.251]
$$

(ii) No causality-in-variance from $R_{S, t}$ to $R_{E, t}$

(iii) No causality-in-variance from $R_{E, t}$ to $R_{S, t}$

$$
H_{0}: \alpha_{S E}=b_{S E}=0 \quad L R=17.9[0.000]
$$

$H_{0}: \alpha_{E S}=b_{E S}=0$

$L R=0.810[0.666]$

(iii) No causality-in-variance from $R_{E, t}$ to $R_{S, t}$

$H_{0}: \alpha_{S E}=b_{S E}=0$

$L R=9.28[0.009]$

(iv) No time-varying correlation

(iv) No time-varying correlation

$$
H_{0}: \alpha^{D C C}=\beta^{D C C}=0 \quad L R=18.8[0.000] \quad H_{0}: \alpha^{D C C}=\beta^{D C C}=0 \quad L R=15.3[0.000]
$$

$\overline{R_{S, t} \text { and } R_{E, t} \text { indicate stock market returns and exchange rate changes, respectively; while } L R \text { indicates likelihood ratio }}$ test statistics. Heteroscedasticity-consistent standard errors are in parentheses (.), whereas $p$-values are reported in [.]. $Q^{2}(p)$ is the multivariate Hosking (1981) test for the $p^{\text {th }}$ order serial correlation on the squared standardised residuals $z_{i t}^{2}$, where $i=S$ (for stock returns), $E$ (for exchange rate changes). The conditional variance equation is specified as $h_{t}=\omega+A \varepsilon_{t-1}^{2}+B h_{t-1}$. The dynamic correlation is specified as $Q_{t}=\left(1-\alpha^{D C C}-\beta^{D C C}\right) \bar{Q}+\alpha^{D C C} \varepsilon_{t-1} \varepsilon_{t-1}^{\prime}+\beta^{D C C} Q_{t-1}$.

**** significant at $1 \%$.

*** significant at $5 \%$.

significant at $10 \%$. 
Table 11

The estimated bivariate UEDCC-GARCH model for Canada.

\begin{tabular}{|c|c|c|c|c|c|}
\hline \multicolumn{3}{|c|}{ Panel A: Pre-crisis period (6/8/2003-8/8/2007) } & \multicolumn{3}{|c|}{ Panel B: Crisis period (15/8/2007-28/12/2011) } \\
\hline & $R_{S, t}(i=S)$ & $R_{E, t}(i=E)$ & \multirow[b]{2}{*}{$\omega_{i}$} & \multirow{2}{*}{$\frac{R_{S, t}(i=S)}{\underset{0.772^{\text {**k* }}}{(0.131)}}$} & \multirow{2}{*}{$\begin{array}{c}R_{E, t}(i=E) \\
0.782^{* * * * *} \\
(0.115)\end{array}$} \\
\hline$\omega_{i}$ & 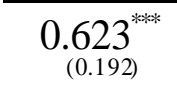 & $\begin{array}{c}0.531^{\text {***** }} \\
(0.118)\end{array}$ & & & \\
\hline$\alpha_{S i}$ & $\begin{array}{c}0.143^{* * *} \\
(0.062)\end{array}$ & $\begin{array}{c}0.069^{*} \\
(0.038)\end{array}$ & $\alpha_{S i}$ & $0_{(0.012)}^{0.085^{* * * *}}$ & $0.104^{* * *}$ \\
\hline$\alpha_{E i}$ & $\begin{array}{c}0.006 \\
(0.007)\end{array}$ & $\underbrace{0.076^{\text {*No* }}}$ & $\alpha_{E i}$ & $\frac{0.121^{\text {***** }}}{(0.040)}$ & 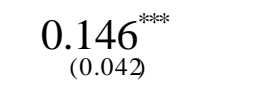 \\
\hline$b_{S i}$ & $0.821^{\text {**o*k* }}$ & $-0.306^{* * *}$ & $b_{S i}$ & ${ }_{(0.054)}^{0.893^{* * *}}$ & $-\underbrace{0.512^{* * * *}}_{(0.107)}$ \\
\hline$b_{E i}$ & $\begin{array}{r}0.013 \\
(0.011)\end{array}$ & ${ }_{(0.057)}^{0.913^{* * * * *}}$ & $b_{E i}$ & $\begin{array}{c}0.672^{\text {****** }} \\
(0.121)\end{array}$ & $0.808^{\text {******* }}$ \\
\hline$\alpha^{D C C}$ & $\begin{array}{r}0.069 \\
(0.070)\end{array}$ & & $\alpha^{D C C}$ & $\begin{array}{c}0.007 \\
(0.018)\end{array}$ & \\
\hline$\beta^{D C C}$ & $\begin{array}{c}0.514^{* * * * *} \\
(0.173)\end{array}$ & & $\beta^{D C C}$ & $0_{(0.079)}^{0.898^{\text {***** }}}$ & \\
\hline Loglik & -665.613 & & Loglik & -906.713 & \\
\hline$Q^{2}(6)$ & $27.846[0$ & & $Q^{2}(6)$ & $31.567[0$. & \\
\hline$Q^{2}(12)$ & $45.238[0$ & & $Q^{2}(12)$ & $52.958[0$. & \\
\hline
\end{tabular}

Hypotheses Testing

(i) No causality-in-variance between $R_{S, t}$ and $R_{E, t}$ Hypotheses Testing

(i) No causality-in-variance between $R_{S, t}$ and $R_{E, t}$ $H_{0}: \alpha_{S E}=\alpha_{E S}=b_{S E}=b_{E S}=0 \quad L R=9.03[0.060]$ $H_{0}: \alpha_{S E}=\alpha_{E S}=b_{S E}=b_{E S}=0 \quad L R=33.9[0.000]$ (ii) No causality-in-variance from $R_{S, t}$ to $R_{E, t}$ (ii) No causality-in-variance from $R_{S, t}$ to $R_{E, t}$ $H_{0}: \alpha_{E S}=b_{E S}=0 \quad L R=0.53[0.764]$ $H_{0}: \alpha_{E S}=b_{E S}=0$ $L R=27.9[0.000]$ (iii) No causality-in-variance from $R_{E, t}$ to $R_{S, t}$

$$
H_{0}: \alpha_{S E}=b_{S E}=0 \quad L R=8.74[0.012]
$$

(iii) No causality-in-variance from $R_{E, t}$ to $R_{S, t}$

(iv) No time-varying correlation

$$
H_{0}: \alpha^{D C C}=\beta^{D C C}=0 \quad L R=1.06[0.586]
$$$$
H_{0}: \alpha_{S E}=b_{S E}=0
$$

(iv) No time-varying correlation

$R_{S, t}$ and $R_{E, t}$ indicate stock market returns and exchange rate changes, respectively; while $L R$ indicates likelihood ratio test statistics. Heteroscedasticity-consistent standard errors are in parentheses (.), whereas $p$-values are reported in [.]. $Q^{2}(p)$ is the multivariate Hosking (1981) test for the $p^{\text {th }}$ order serial correlation on the squared standardised residuals $z_{i t}^{2}$, where $i=S$ (for stock returns), $E$ (for exchange rate changes). The conditional variance equation is specified as $h_{t}=\omega+A \varepsilon_{t-1}^{2}+B h_{t-1}$. The dynamic correlation is specified as $Q_{t}=\left(1-\alpha^{D C C}-\beta^{D C C}\right) \bar{Q}+\alpha^{D C C} \varepsilon_{t-1} \varepsilon_{t-1}^{\prime}+\beta^{D C C} Q_{t-1}$.

**** significant at $1 \%$.

** significant at $5 \%$.

" significant at $10 \%$. 
Table 12

The estimated bivariate UEDCC-GARCH model for Switzerland.

\begin{tabular}{|c|c|c|c|c|c|}
\hline \multicolumn{3}{|c|}{ Panel A: Pre-crisis period (6/8/2003-8/8/2007) } & \multicolumn{3}{|c|}{ Panel B: Crisis period (15/8/2007-28/12/2011) } \\
\hline & $R_{S, t}(i=S)$ & $R_{E, t}(i=E)$ & & $R_{S, t}(i=S)$ & $R_{E, t}(i=E)$ \\
\hline$\omega_{i}$ & $\begin{array}{c}0.123 \\
(0.101)\end{array}$ & $\begin{array}{c}0.094 \\
(0.064)\end{array}$ & $\omega_{i}$ & $\begin{array}{c}0.767^{\text {***** }} \\
(0.017)\end{array}$ & $0.542^{\text {**** }}$ \\
\hline$\alpha_{S i}$ & $\frac{0.073^{* *}}{(0.034)}$ & $\begin{array}{c}0.073 \\
(0.061)\end{array}$ & $\alpha_{S i}$ & $0_{(0.006)}^{0.044^{\text {**** }}}$ & $\begin{array}{c}0.367^{\text {***** }} \\
(0.015)\end{array}$ \\
\hline$\alpha_{E i}$ & $\underset{(0.005)}{0.006}$ & $\underset{(0.043)}{0.032}$ & $\alpha_{E i}$ & 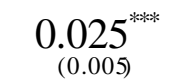 & $\begin{array}{c}0.216^{* \text { *** }} \\
(0.019)\end{array}$ \\
\hline$b_{S i}$ & $\begin{array}{l}0.719^{\text {***** }} \\
(0.069)\end{array}$ & ${ }_{(0.122)}^{0.216^{*}}$ & $b_{S i}$ & $\begin{array}{c}0.837^{* * * *} \\
(0.101)\end{array}$ & $-\underbrace{0.346^{* * * *}}_{(0.058)}$ \\
\hline$b_{E i}$ & $\begin{array}{c}0.106 \\
(0.891)\end{array}$ & $0.832^{\text {******* }}$ & $b_{E i}$ & $0_{(0.002)}^{0.105^{\text {***** }}}$ & $\begin{array}{c}0.773^{\text {***** }} \\
(0.025)\end{array}$ \\
\hline$\alpha^{D C C}$ & $\begin{array}{c}0.029^{*} \\
(0.017)\end{array}$ & & $\alpha^{D C C}$ & $\underbrace{0.097^{* *}}_{(0.045)}$ & \\
\hline$\beta^{D C C}$ & $0.921^{0.021 * *}$ & & $\beta^{D C C}$ & 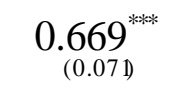 & \\
\hline Loglik & -507.889 & & Loglik & -842.977 & \\
\hline$Q^{2}(6)$ & $34.358[0$ & & $Q^{2}(6)$ & $24.635[0$ & \\
\hline$Q^{2}(12)$ & $50.099[0$ & & $Q^{2}(12)$ & $37.349[0$ & \\
\hline
\end{tabular}

Hypotheses Testing

Hypotheses Testing

(i) No causality-in-variance between $R_{S, t}$ and $R_{E, t}$

(i) No causality-in-variance between $R_{S, t}$ and $R_{E, t}$ $H_{0}: \alpha_{S E}=\alpha_{E S}=b_{S E}=b_{E S}=0 \quad L R=7.38[0.116]$ $H_{0}: \alpha_{S E}=\alpha_{E S}=b_{S E}=b_{E S}=0 \quad L R=22.7[0.000]$

(ii) No causality-in-variance from $R_{S, t}$ to $R_{E, t}$

$$
H_{0}: \alpha_{E S}=b_{E S}=0 \quad L R=3.88[0.143]
$$

(ii) No causality-in-variance from $R_{S, t}$ to $R_{E, t}$

(iii) No causality-in-variance from $R_{E, t}$ to $R_{S, t}$

$$
H_{0}: \alpha_{S E}=b_{S E}=0 \quad L R=4.68[0.096]
$$

$H_{0}: \alpha_{E S}=b_{E S}=0 \quad L R=19.6[0.000]$

(iii) No causality-in-variance from $R_{E, t}$ to $R_{S, t}$

$H_{0}: \alpha_{S E}=b_{S E}=0 \quad L R=17.8[0.000]$

(iv) No time-varying correlation

$H_{0}: \alpha^{D C C}=\beta^{D C C}=0 \quad L R=11.7[0.002] \quad H_{0}: \alpha^{D C C}=\beta^{D C C}=0$

(iv) No time-varying correlation

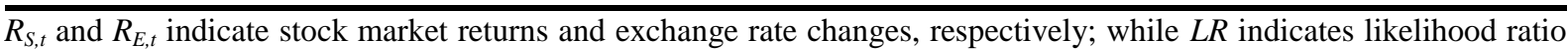
test statistics. Heteroscedasticity-consistent standard errors are in parentheses (.), whereas $p$-values are reported in [.]. $Q^{2}(p)$ is the multivariate Hosking (1981) test for the $p^{\text {th }}$ order serial correlation on the squared standardised residuals $z_{i t}^{2}$, where $i=S$ (for stock returns), $E$ (for exchange rate changes). The conditional variance equation is specified as $h_{t}=\omega+A \varepsilon_{t-1}^{2}+B h_{t-1}$. The dynamic correlation is specified as $Q_{t}=\left(1-\alpha^{D C C}-\beta^{D C C}\right) \bar{Q}+\alpha^{D C C} \varepsilon_{t-1} \varepsilon_{t-1}^{\prime}+\beta^{D C C} Q_{t-1}$.

*** significant at $1 \%$.

** significant at $5 \%$.

* significant at $10 \%$. 
Table 13

The estimated bivariate UEDCC-GARCH model for the UK.

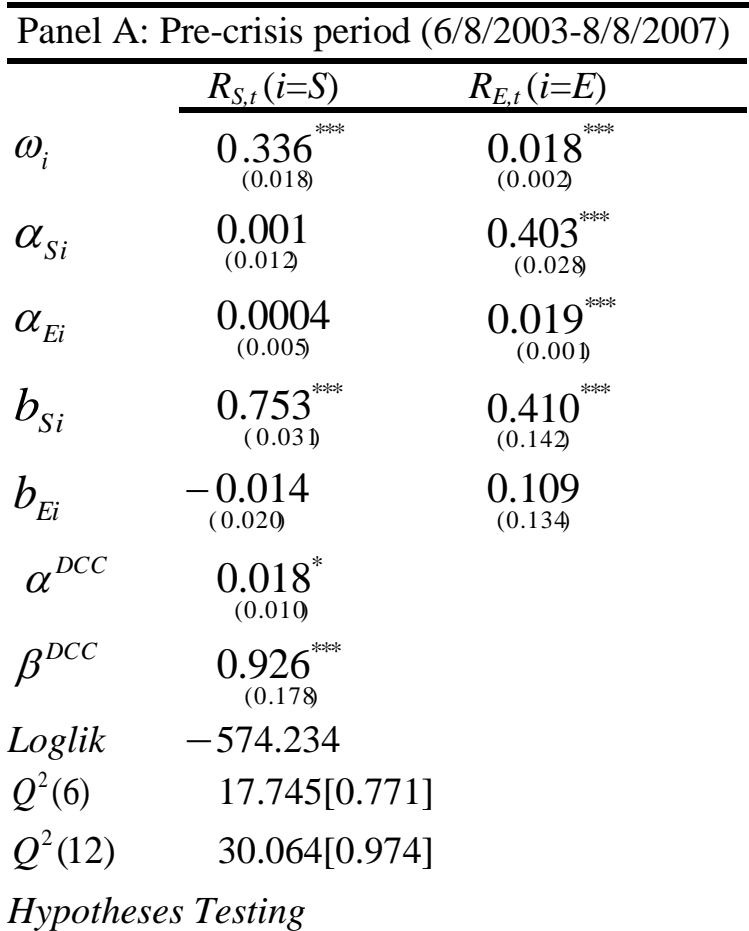

(i) No causality-in-variance between $R_{S, t}$ and $R_{E, t}$

\begin{tabular}{|c|c|c|}
\hline \multicolumn{3}{|c|}{ Panel B: Crisis period (15/8/2007-28/12/2011) } \\
\hline & $R_{S, t}(i=S)$ & $R_{E, t}(i=E)$ \\
\hline$\omega_{i}$ & $\begin{array}{c}0.606^{*} \\
(0.360)\end{array}$ & $\begin{array}{c}0.006 \\
(0.063)\end{array}$ \\
\hline$\alpha_{S i}$ & $0_{(0.108)}^{0.215^{* *}}$ & $\begin{array}{c}0.228 \\
(0.162)\end{array}$ \\
\hline$\alpha_{E i}$ & $\underset{(0.003)}{0.001}$ & $0_{(0.057)}^{0.107^{*}}$ \\
\hline$b_{S i}$ & 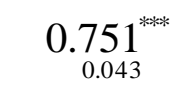 & $-\underset{(0.418)}{0.105}$ \\
\hline$b_{E i}$ & $\begin{array}{c}0.009 \\
(0.010)\end{array}$ & $\begin{array}{c}0.822^{* * * * *} \\
(0.059)\end{array}$ \\
\hline$\alpha^{D C C}$ & $0_{(0.014)}^{0.028^{* *}}$ & \\
\hline$\beta^{D C C}$ & $\frac{0.620^{* * * * *}}{(0.038)}$ & \\
\hline Loglik & -915.689 & \\
\hline$Q^{2}(6)$ & $11.914[0$ & \\
\hline$Q^{2}(12)$ & $36.507[0$ & \\
\hline
\end{tabular}

Hypotheses Testing

(i) No causality-in-variance between $R_{S, t}$ and $R_{E, t}$ $H_{0}: \alpha_{S E}=\alpha_{E S}=b_{S E}=b_{E S}=0 \quad L R=15.3[0.003]$ $H_{0}: \alpha_{S E}=\alpha_{E S}=b_{S E}=b_{E S}=0 \quad L R=4.83[0.305]$

(ii) No causality-in-variance from $R_{S, t}$ to $R_{E, t}$

$$
H_{0}: \alpha_{E S}=b_{E S}=0 \quad L R=0.16[0.919]
$$

(ii) No causality-in-variance from $R_{S, t}$ to $R_{E, t}$

(iii) No causality-in-variance from $R_{E, t}$ to $R_{S, t}$

$$
H_{0}: \alpha_{E S}=b_{E S}=0
$$

$H_{0}: \alpha_{S E}=b_{S E}=0$

$$
L R=20.6[0.000]
$$

(iii) No causality-in-variance from $R_{E, t}$ to $R_{S, t}$

(iv) No time-varying correlation

$$
H_{0}: \alpha^{D C C}=\beta^{D C C}=0 \quad L R=7.57[0.022] \quad H_{0}: \alpha^{D C C}=\beta^{D C C}=0
$$$$
H_{0}: \alpha_{S E}=b_{S E}=0
$$

(iv) No time-varying correlation

$R_{S, t}$ and $R_{E, t}$ indicate stock market returns and exchange rate changes, respectively; while $L R$ indicates likelihood ratio test statistics. Heteroscedasticity-consistent standard errors are in parentheses (.), whereas $p$-values are reported in [.]. $Q^{2}(p)$ is the multivariate Hosking (1981) test for the $p^{\text {th }}$ order serial correlation on the squared standardised residuals $z_{i t}^{2}$, where $i=S$ (for stock returns), $E$ (for exchange rate changes). The conditional variance equation is specified as $h_{t}=\omega+A \varepsilon_{t-1}^{2}+B h_{t-1}$. The dynamic correlation is specified as $Q_{t}=\left(1-\alpha^{D C C}-\beta^{D C C}\right) \bar{Q}+\alpha^{D C C} \varepsilon_{t-1} \varepsilon_{t-1}^{\prime}+\beta^{D C C} Q_{t-1}$.

*** significant at $1 \%$.

*** significant at $5 \%$.

* significant at $10 \%$. 


\section{Appendix}

Table A1: Summary of descriptive statistics for stock returns and traded-weighted exchange rate changes.

\begin{tabular}{|c|c|c|c|c|c|c|c|}
\hline \multicolumn{4}{|c|}{ Panel A: Pre-crisis period $(6 / 8 / 2003-8 / 8 / 2007)$} & \multirow[b]{2}{*}{ Euro area } & \multirow[b]{2}{*}{ Japan } & \multirow[b]{2}{*}{ Switzerland } & \multirow[b]{2}{*}{ US } \\
\hline Statistics & Variable & Canada & UK & & & & \\
\hline \multirow[t]{2}{*}{ Mean } & $\overline{R_{E, t}}$ & 0.128 & 0.045 & 0.034 & -0.044 & -0.022 & -0.078 \\
\hline & $R_{S, t}$ & 0.313 & 0.216 & 0.278 & 0.288 & 0.279 & 0.209 \\
\hline \multirow[t]{2}{*}{ St. Dev } & $R_{E, t}$ & 0.987 & 0.692 & 0.573 & 0.976 & 0.468 & 0.887 \\
\hline & $R_{S, t}$ & 1.567 & 1.456 & 1.805 & 2.307 & 1.638 & 1.327 \\
\hline \multirow[t]{2}{*}{ Skewness } & $R_{E, t}$ & -0.152 & -0.060 & 0.040 & 0.300 & 0.418 & 0.256 \\
\hline & $R_{S, t}$ & -0.584 & -0.861 & -0.747 & -0.441 & -0.714 & -0.412 \\
\hline \multirow[t]{2}{*}{ Ex. kurtosis } & $R_{E, t}$ & 2.875 & 2.977 & 4.335 & 3.370 & 3.513 & 3.009 \\
\hline & $R_{S, t}$ & 3.497 & 5.227 & 4.056 & 3.445 & 4.012 & 3.137 \\
\hline \multirow[t]{2}{*}{ JB } & $R_{E, t}$ & 0.942 & 0.133 & $15.59^{* * *}$ & 4.341 & $8.398^{* * * *}$ & 2.284 \\
\hline & $R_{S, t}$ & $14.04^{* * *}$ & $69.06^{* * * *}$ & $29.19^{* * *}$ & $8.527^{* *}$ & $26.70^{* * * *}$ & $6.098^{* *}$ \\
\hline \multirow[t]{2}{*}{$L B(10)$} & $R_{E, t}$ & 8.299 & 15.37 & 14.91 & $17.03^{*}$ & 14.04 & 3.454 \\
\hline & $R_{S, t}$ & 12.68 & 12.43 & 9.081 & 10.43 & 7.159 & $16.68^{*}$ \\
\hline \multirow[t]{2}{*}{$L B^{2}(10)$} & $R_{E, t}$ & 14.11 & 6.917 & $29.12^{* * *}$ & $23.68^{* * * *}$ & $23.87^{* * *}$ & 11.08 \\
\hline & $R_{S, t}$ & $24.28^{* * *}$ & 7.402 & 4.876 & $16.02^{*}$ & 8.148 & 5.054 \\
\hline \multicolumn{8}{|c|}{ Panel B: Crisis period $(15 / 8 / 2007-28 / 12 / 2011)$} \\
\hline Statistics & Variable & Canada & UK & Euro area & Japan & Switzerland & US \\
\hline \multirow[t]{2}{*}{ Mean } & $R_{E, t}$ & 0.0153 & -0.110 & -0.024 & 0.186 & 0.122 & -0.047 \\
\hline & $R_{S, t}$ & -0.046 & -0.045 & -0.271 & -0.294 & -0.168 & -0.051 \\
\hline \multirow[t]{2}{*}{ St. Dev } & $R_{E, t}$ & 1.754 & 1.2755 & 0.995 & 1.655 & 1.344 & 1.160 \\
\hline & $R_{S, t}$ & 2.952 & 3.061 & 4.526 & 3.755 & 2.926 & 3.159 \\
\hline \multirow[t]{2}{*}{ Skewness } & $R_{E, t}$ & -0.217 & 0.250 & 0.432 & 0.595 & -1.634 & -0.554 \\
\hline & $R_{S, t}$ & -0.817 & -0.753 & -0.677 & -0.834 & -0.485 & -0.936 \\
\hline \multirow[t]{2}{*}{ Ex. kurtosis } & $R_{E, t}$ & 4.184 & 6.072 & 6.587 & 4.808 & 19.83 & 6.274 \\
\hline & $R_{S, t}$ & 6.046 & 4.502 & 4.939 & 8.018 & 6.130 & 6.997 \\
\hline \multirow[t]{2}{*}{ JB } & $R_{E, t}$ & $15.12^{* * *}$ & $92.04^{* * *}$ & $129.3^{* * *}$ & $44.53^{\text {*** }}$ & 2793. .** $^{* * *}$ & $113.5^{* * *}$ \\
\hline & $R_{S, t}$ & $113.5^{* * *}$ & $43.01^{* * *}$ & $53.18^{* * *}$ & $265.7^{* * *}$ & $102.0^{* * *}$ & $185.1^{\text {*** }}$ \\
\hline \multirow[t]{2}{*}{$L B(10)$} & $R_{E, t}$ & 15.36 & $20.98^{* *}$ & $17.59^{*}$ & 12.48 & $21.87^{* *}$ & $16.77^{*}$ \\
\hline & $R_{S, t}$ & $34.12^{* * * *}$ & $17.91^{*}$ & $27.24^{* * *}$ & 13.78 & 14.47 & $16.50^{*}$ \\
\hline \multirow[t]{2}{*}{$L B^{2}(10)$} & $R_{E, t}$ & $115.3^{* * *}$ & $106.1^{* * * *}$ & $38.49^{* * *}$ & $51.49^{\text {**** }}$ & $36.63^{* * *}$ & $21.72^{* *}$ \\
\hline & $R_{S, t}$ & $54.80^{* * * *}$ & $35.51^{* * * *}$ & $27.24^{* * * *}$ & $31.01^{* * * *}$ & $46.75^{* * *}$ & $32.21^{* * * *}$ \\
\hline
\end{tabular}

$R_{S, t}$ and $R_{E, t}$ indicate stock market returns and exchange rate changes, respectively. $L B(p)$ and $L B^{2}(p)$ are Ljung and Box (1978) tests for the $p^{\text {th }}$ order serial correlation on the returns $R_{i, t}$ and squared returns $R_{i, t}^{2}$, respectively, where $i=S$ (for stock returns), $E$ (for exchange rate changes). $J B$ is the Jarque-Bera test for normality.

**** significant at $1 \%$.

*** significant at $5 \%$.

* significant at $10 \%$. 
Table A2: Results of the Engle and Granger (1987) cointegration test based on residuals.

\begin{tabular}{cccc}
\hline Countries & Sample & $s_{t}$ on $e_{t}$ & $e_{t}$ on $s_{t}$ \\
\hline US & Pre-crisis & $-1.718(0)$ & $-2.838(0)$ \\
& Crisis & $-2.712(0)$ & $-2.978(0)$ \\
UK & Pre-crisis & $-1.138(5)$ & $-2.306(4)$ \\
& Crisis & $-1.809(0)$ & $-2.246(0)$ \\
Euro area & Pre-crisis & $-1.627(5)$ & $-2.696(0)$ \\
& Crisis & $-2.155(0)$ & $-1.485(0)$ \\
Canada & Pre-crisis & $-2.568(0)$ & $-2.550(0)$ \\
& Crisis & $-3.003(4)$ & $-1.982(8)$ \\
Japan & Pre-crisis & $-5.149(0)^{* * *}$ & $-4.789(0)$ \\
& Crisis & $-2.218(0)$ & $-1.526(0)$ \\
Switzerland & Pre-crisis & $-2.201(1)$ & $-2.640(0)$ \\
& Crisis & $-1.899(0)$ & $-0.694(0)$ \\
\hline
\end{tabular}

The pairwise Engle and Granger (1987) test is conducted by regressing the log of stock market price $\left(s_{t}\right)$ on the log of the exchange rate $\left(e_{t}\right)$, as well as in the other way around. The proper lag order is chosen by considering the Akaike information Criterion (AIC), representing in parenthesis. The 1\%, $5 \%$, and $10 \%$ critical values of the MacKinnon (1991) for the augmented Dickey-Fuller test statistic are $-3.89,-3.33$, and -3.04 , respectively.

**** significant at $1 \%$. 
Table A3: Results of the Johansen's (1995) cointegration tests between stock market prices and exchange rates.

\begin{tabular}{|c|c|c|c|c|c|c|c|c|c|}
\hline Country & Sample & Lags & $r$ & Eigenvalues & Trace test & Trace Test* & $95 \%$ C.V & $p$-value & $p$-value* \\
\hline \multirow[t]{4}{*}{ US } & \multirow{2}{*}{$\begin{array}{l}\text { Pre- } \\
\text { crisis }\end{array}$} & \multirow[t]{2}{*}{1} & $r=0$ & 0.044 & 10.93 & 10.88 & 15.40 & 0.219 & 0.222 \\
\hline & & & $r \leq 1$ & 0.007 & 1.519 & 1.517 & 3.841 & 0.218 & 0.218 \\
\hline & \multirow[t]{2}{*}{ Crisis } & \multirow[t]{2}{*}{1} & $r=0$ & 0.043 & 11.86 & 11.82 & 15.40 & 0.165 & 0.167 \\
\hline & & & $r \leq 1$ & 0.008 & 1.843 & 1.840 & 3.841 & 0.175 & 0.175 \\
\hline \multirow[t]{4}{*}{ UK } & \multirow{2}{*}{$\begin{array}{l}\text { Pre- } \\
\text { crisis }\end{array}$} & \multirow[t]{2}{*}{1} & $r=0$ & 0.043 & 10.13 & 10.09 & 15.40 & 0.275 & 0.278 \\
\hline & & & $r \leq 1$ & 0.005 & 1.031 & 1.029 & 3.841 & 0.310 & 0.310 \\
\hline & \multirow[t]{2}{*}{ Crisis } & \multirow[t]{2}{*}{1} & $r=0$ & 0.035 & 11.40 & 11.36 & 15.40 & 0.191 & 0.191 \\
\hline & & & $r \leq 1$ & 0.014 & 3.289 & 3.285 & 3.841 & 0.070 & 0.070 \\
\hline \multirow[t]{4}{*}{ Japan } & \multirow{2}{*}{$\begin{array}{l}\text { Pre- } \\
\text { crisis }\end{array}$} & \multirow[t]{2}{*}{2} & $r=0$ & 0.102 & 22.58 & 22.23 & 15.40 & $0.003^{* * *}$ & $0.003^{* * *}$ \\
\hline & & & $r \leq 1$ & 0.001 & 0.200 & 0.194 & 3.841 & 0.655 & 0.660 \\
\hline & \multirow[t]{2}{*}{ Crisis } & \multirow[t]{2}{*}{2} & $r=0$ & 0.023 & 6.407 & 6.328 & 15.40 & 0.652 & 0.661 \\
\hline & & & $r \leq 1$ & 0.005 & 1.110 & 0.963 & 3.841 & 0.292 & 0.327 \\
\hline \multirow[t]{4}{*}{ Euro area } & \multirow{2}{*}{$\begin{array}{l}\text { Pre- } \\
\text { crisis }\end{array}$} & \multirow[t]{2}{*}{1} & $r=0$ & 0.038 & 8.389 & 8.356 & 15.40 & 0.432 & 0.435 \\
\hline & & & $r \leq 1$ & 0.002 & 0.381 & 0.380 & 3.841 & 0.537 & 0.538 \\
\hline & \multirow[t]{2}{*}{ Crisis } & \multirow[t]{2}{*}{2} & $r=0$ & 0.020 & 6.472 & 6.385 & 15.40 & 0.645 & 0.655 \\
\hline & & & $r \leq 1$ & 0.009 & 1.989 & 1.540 & 3.841 & 0.158 & 0.215 \\
\hline \multirow[t]{4}{*}{ Canada } & \multirow{2}{*}{$\begin{array}{l}\text { Pre- } \\
\text { crisis }\end{array}$} & \multirow[t]{2}{*}{1} & $r=0$ & 0.033 & 8.126 & 8.094 & 15.40 & 0.459 & 0.463 \\
\hline & & & $r \leq 1$ & 0.006 & 1.209 & 1.207 & 3.841 & 0.272 & 0.272 \\
\hline & \multirow[t]{2}{*}{ Crisis } & \multirow[t]{2}{*}{5} & $r=0$ & 0.040 & 11.27 & 11.27 & 15.40 & 0.198 & 0.198 \\
\hline & & & $r \leq 1$ & 0.009 & 2.040 & 2.040 & 3.841 & 0.153 & 0.153 \\
\hline \multirow{4}{*}{ Switzerland } & \multirow{2}{*}{$\begin{array}{l}\text { Pre- } \\
\text { crisis }\end{array}$} & \multirow[t]{2}{*}{1} & $r=0$ & 0.034 & 8.138 & 8.106 & 15.40 & 0.458 & 0.461 \\
\hline & & & $r \leq 1$ & 0.004 & 0.841 & 0.840 & 3.841 & 0.359 & 0.359 \\
\hline & \multirow[t]{2}{*}{ Crisis } & \multirow[t]{2}{*}{1} & $r=0$ & 0.022 & 5.580 & 5.560 & 15.40 & 0.746 & 0.748 \\
\hline & & & $r \leq 1$ & 0.002 & 0.498 & 0.497 & 3.841 & 0.480 & 0.481 \\
\hline
\end{tabular}

The Table reports the Johansen trace test statistics (Johansen, 1995) and the Bartlett corrected trace test statistics (Johansen, 2002) denoted by Trace test ${ }^{*} . r$ is the cointegrating rank. The lag length is selected using the Akaike Information Criterion (AIC), subject to correction for serial correlation by the inclusion of further lags. The last two columns report the respective $p$-values.

**** significant at $1 \%$. 
US

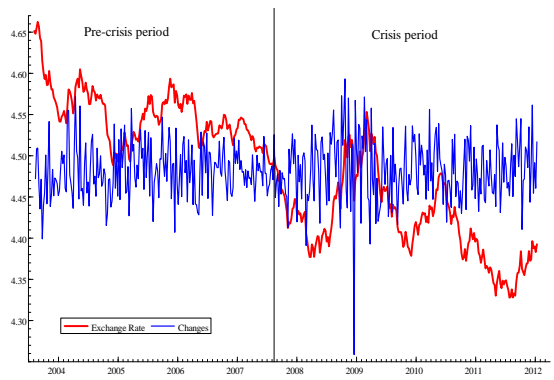

Japan

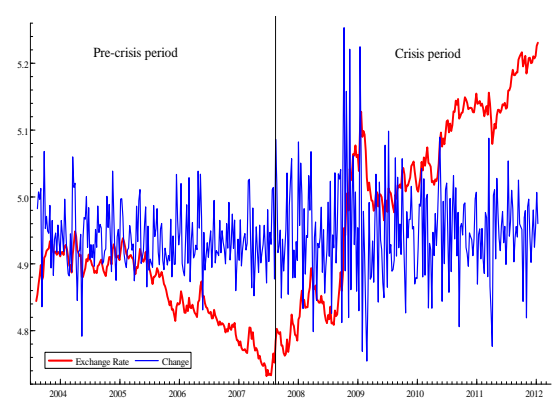

UK

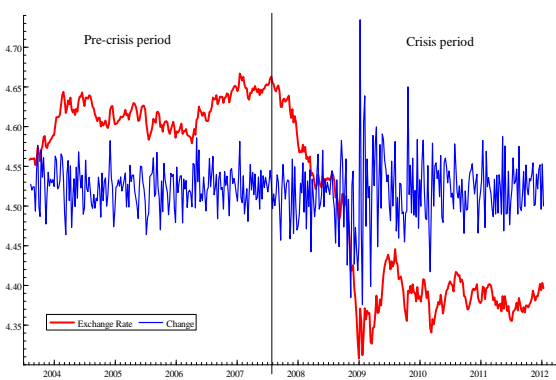

Canada

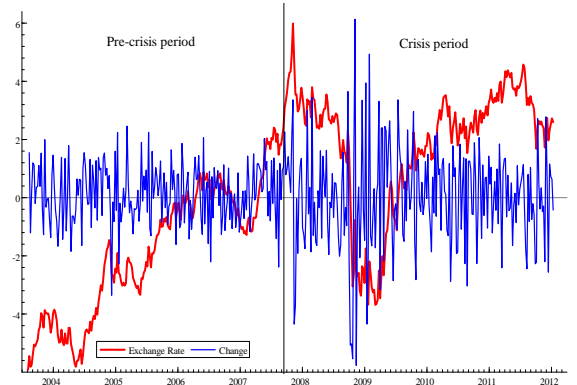

Euro area

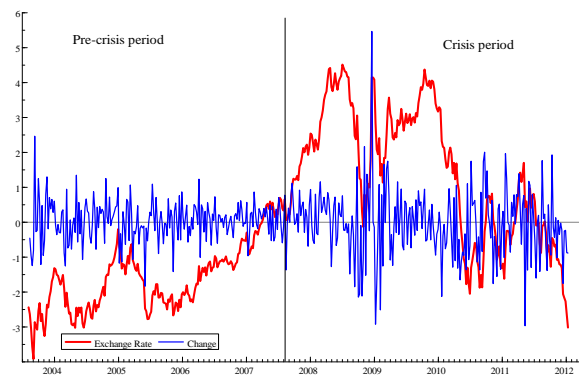

Switzerland

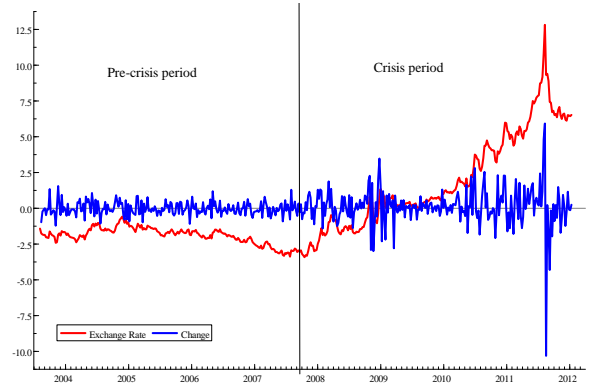

Fig. 1a. Weekly trade-weighted exchange rates with their corresponding changes over the sample period (August 6, 2003- December 28, 2011).

US

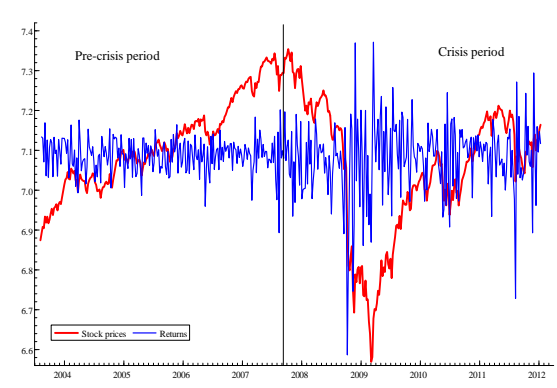

Japan

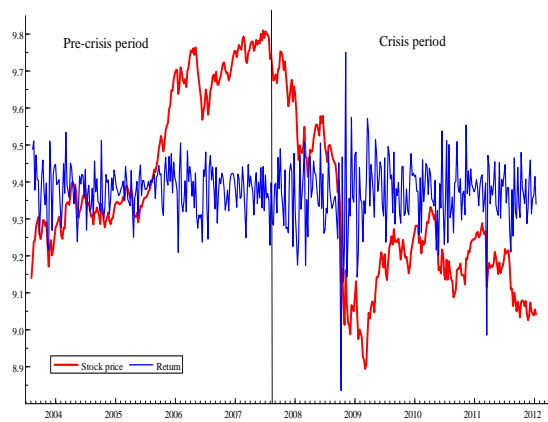

UK

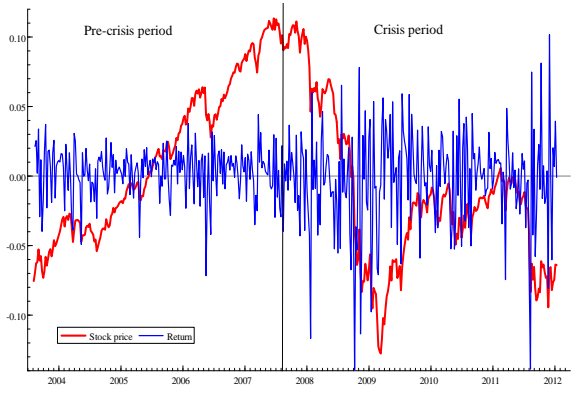

Canada

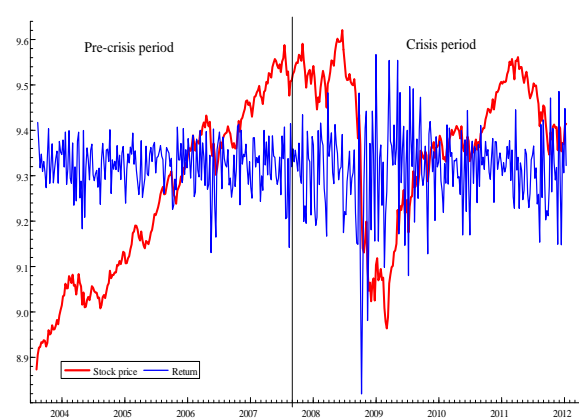

Euro area

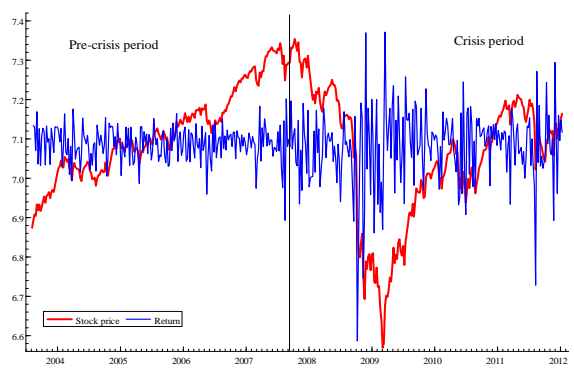

Switzerland

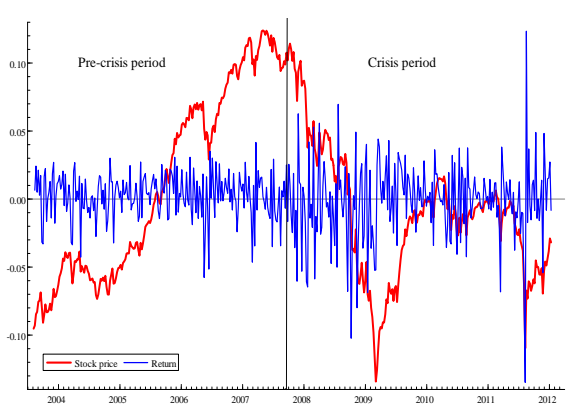

Fig. 1b. Weekly stock market prices with their corresponding returns over the sample period (August 6, 2003December 28, 2011). 

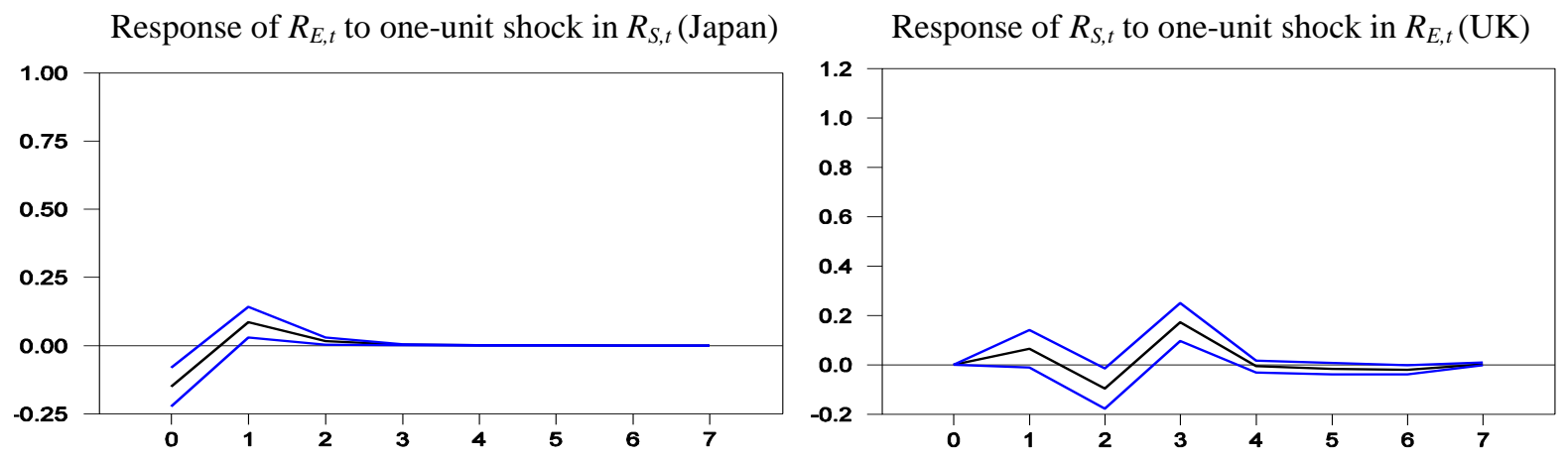

Fig. 2a. Generalized impulse responses of significant short-run Granger causality between stock returns and exchange rate changes in the pre-crisis period (August 6, 2003-August 8, 2007). 
Response of $R_{E, t}$ to one-unit shock in $R_{S, t}(\mathrm{US})$

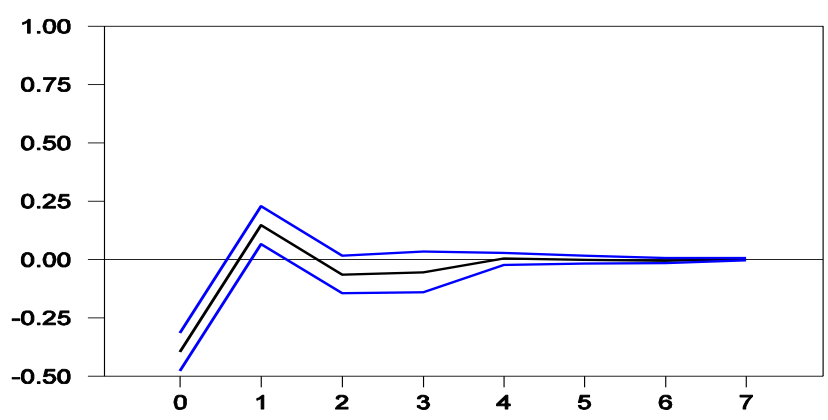

Response of $R_{S, t}$ to one-unit shock in $R_{E, t}$ (euro area)

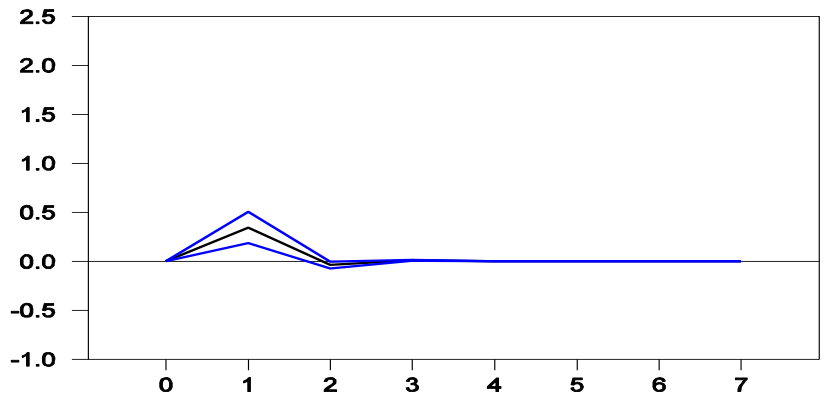

Response of $R_{S, t}$ to one-unit shock in $R_{E, t}$ (Switzerland)

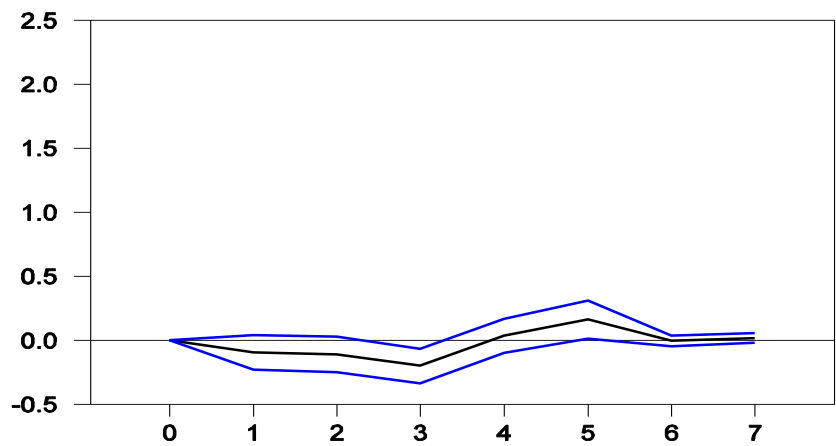

Response of $R_{E, t}$ to one-unit shock in $R_{S, t}(\mathrm{UK})$

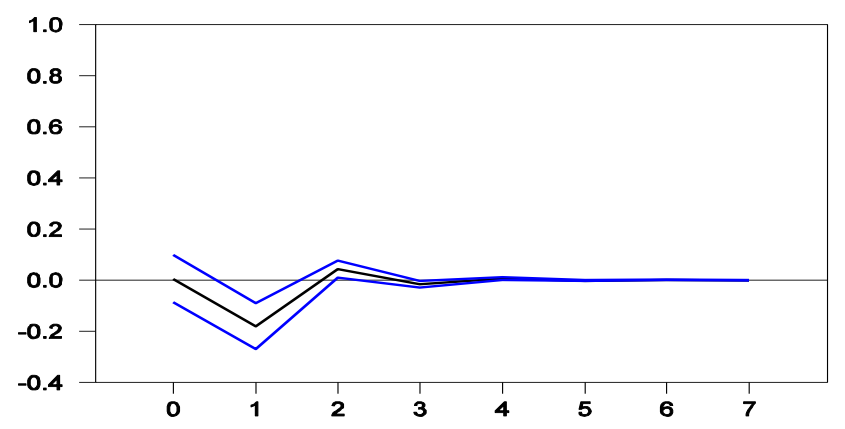

Response of $R_{S, t}$ to one-unit shock in $R_{E, t}$ (Canada)

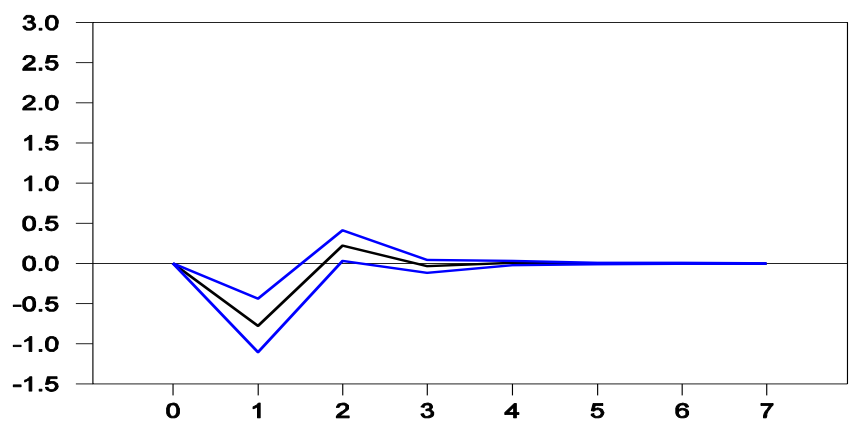

Response of $R_{E, t}$ to one-unit shock in $R_{S, t}$ (euro area)

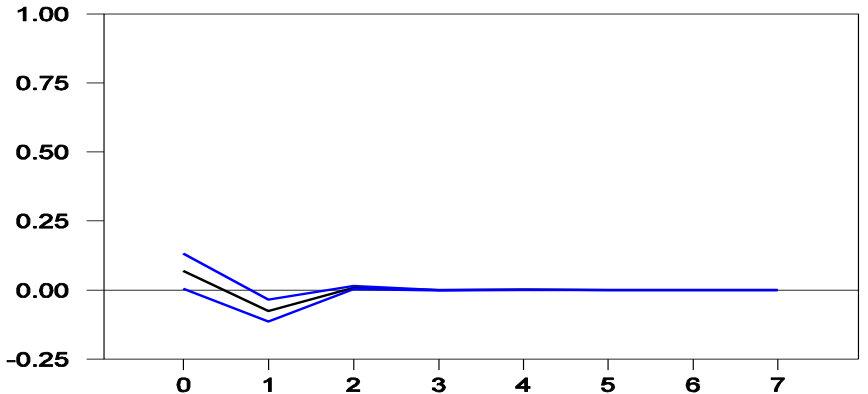

Response of $R_{E, t}$ to one-unit shock in $R_{S, t}$ (Switzerland)

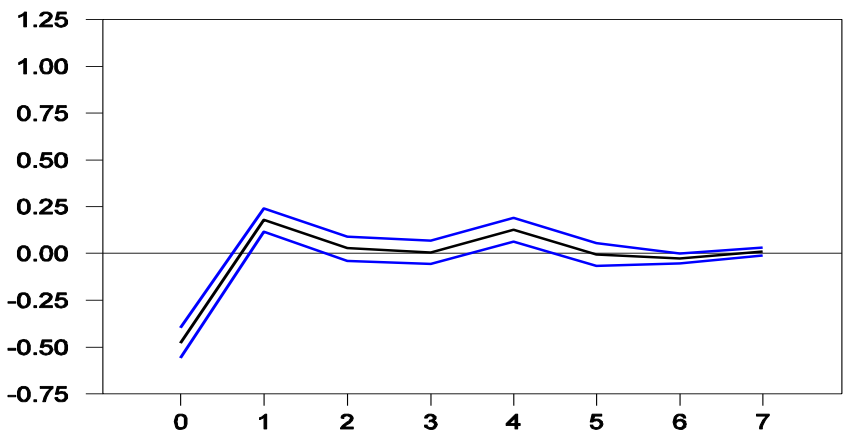

Fig. 2b. Generalized impulse responses of significant short-run Granger causality between stock returns and exchange rate changes in the crisis period (August 15, 2007-December 28, 2011). 

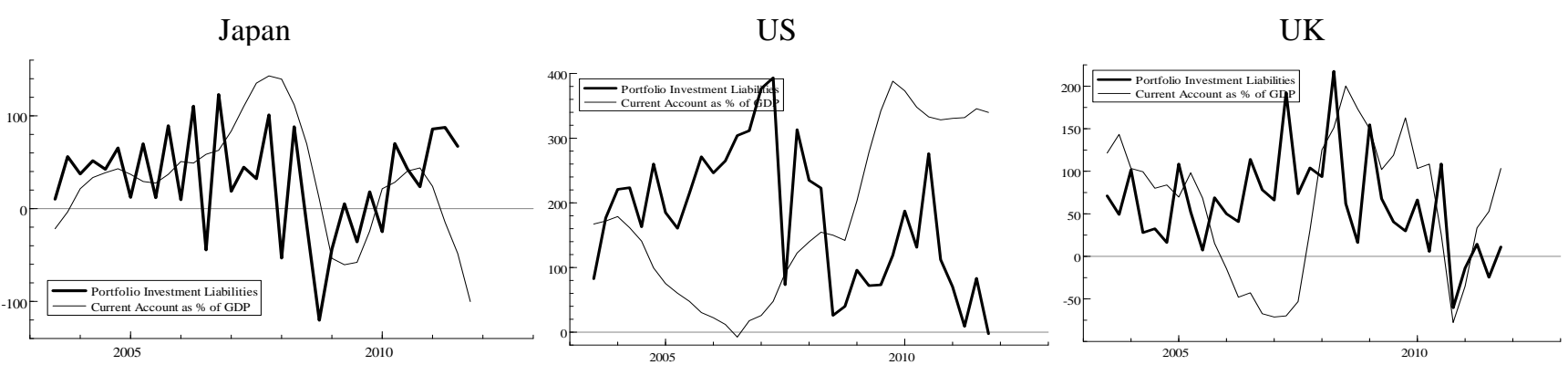

Canada

Switzerland

Euro area
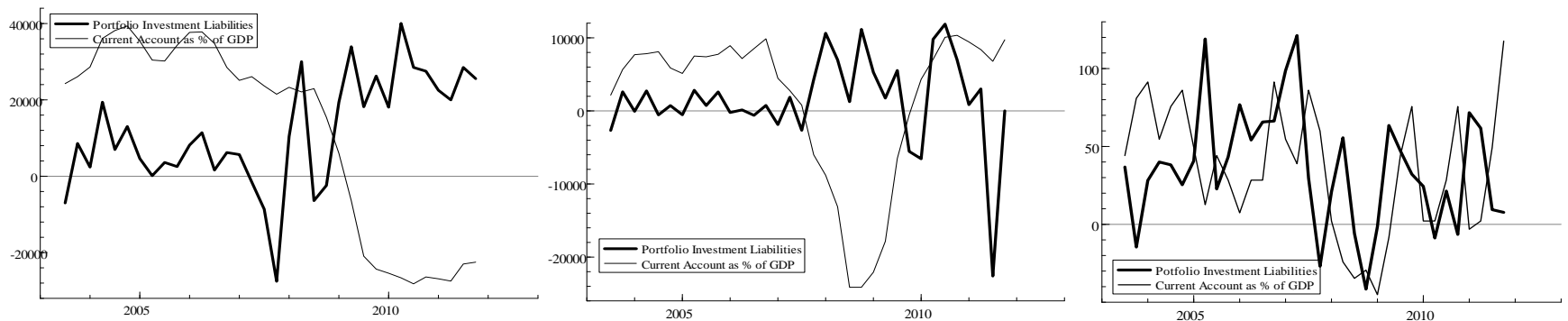

Fig. 3. The evolution of portfolio investment liabilities and current account as a percentage of GDP over the sample period (August 6, 2003-December 28, 2011) (Source: Bloomberg). 

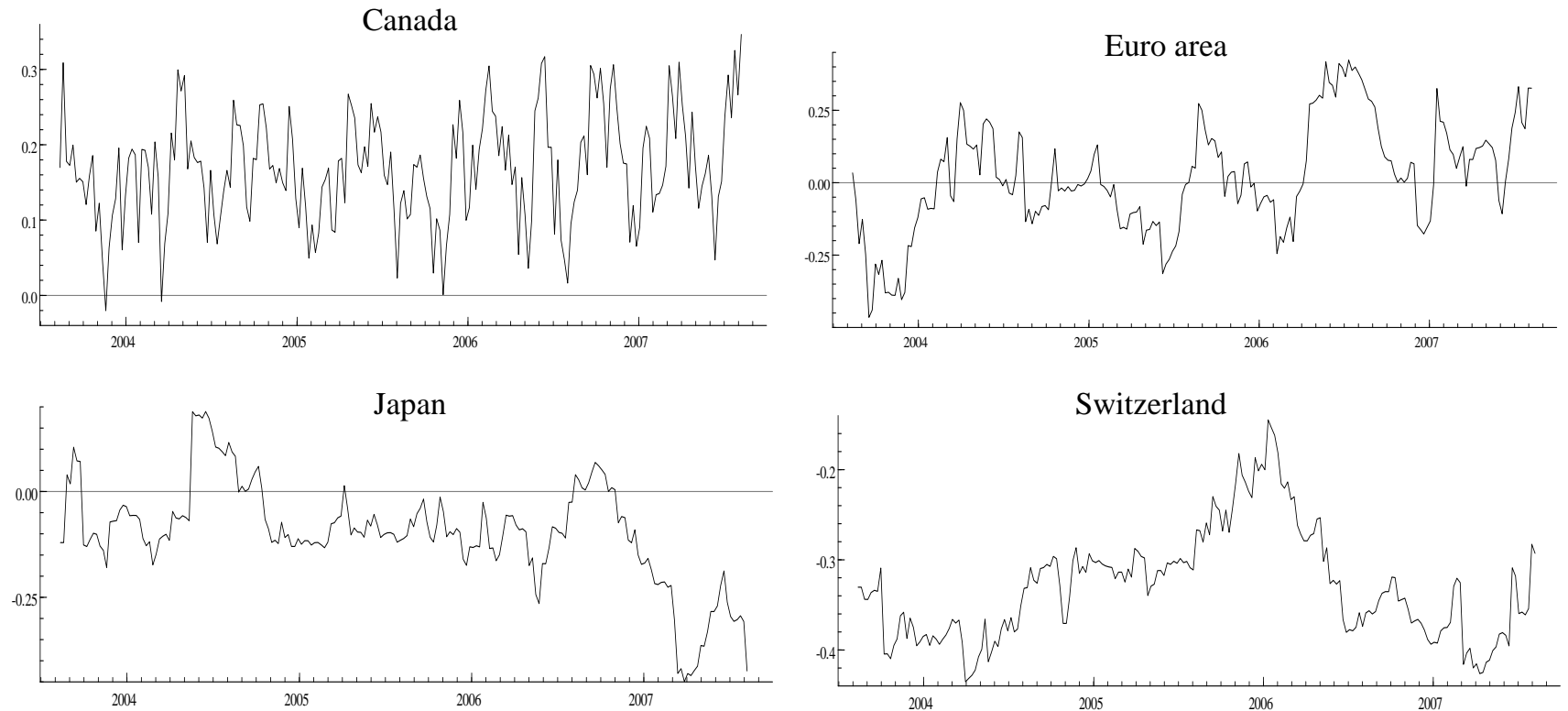

UK

US
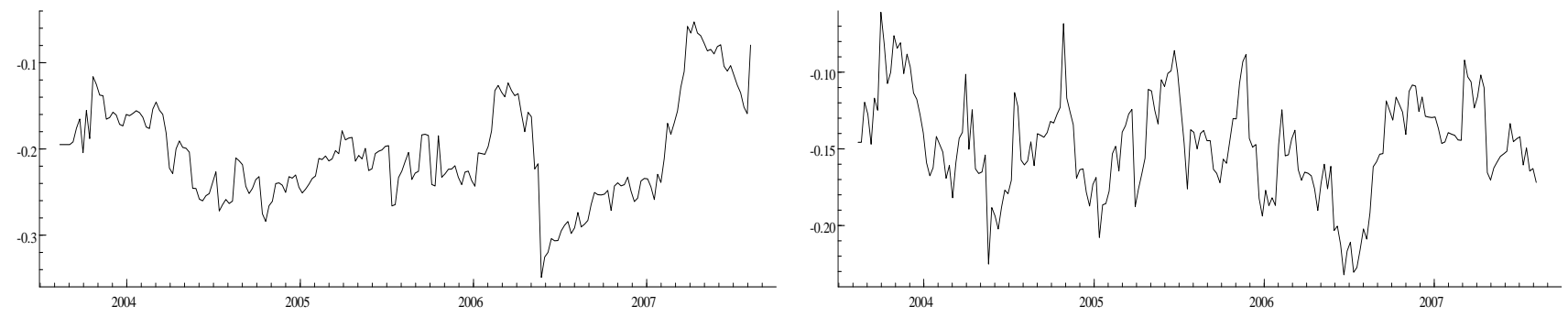

Fig. 4a. The evolution of the dynamic conditional correlation between stock returns and exchange rate changes over the pre-crisis period (August 6, 2003-August 8, 2007). 

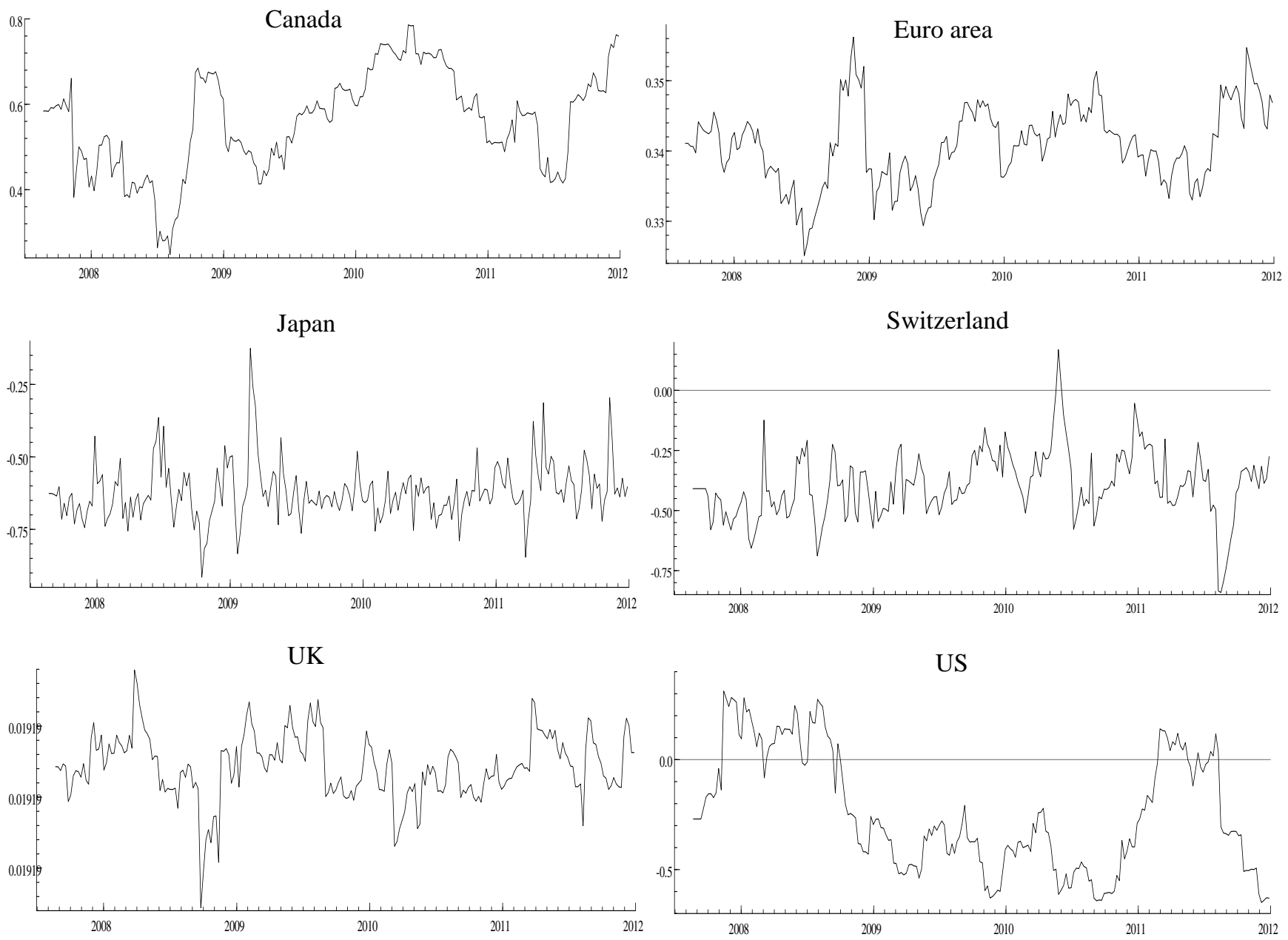

Fig. 4b. The evolution of the dynamic conditional correlation between stock returns and exchange rate changes over the crisis period (August 15, 2007-December 28, 2011). 